Interfaces: Adsorption, Reactions, Films, Forces, Measurement Techniques, Charge Transfer, Electrochemistry, Electrocatalysis, Energy Production and Storage

\title{
Monitoring of CO Binding Sites on Stepped Pt Single Crystal Electrodes in Alkaline Solutions by in situ FTIR Spectroscopy
}

Manuel J. S. Farias, Carlos Buso-Rogero, Auro A. Tanaka, Enrique Herrero, and Juan Miguel Feliu

Langmuir, Just Accepted Manuscript • DOI: 10.1021/acs.langmuir.9b02928 • Publication Date (Web): 17 Dec 2019

Downloaded from pubs.acs.org on December 17, 2019

\section{Just Accepted}

"Just Accepted" manuscripts have been peer-reviewed and accepted for publication. They are posted online prior to technical editing, formatting for publication and author proofing. The American Chemical Society provides "Just Accepted" as a service to the research community to expedite the dissemination of scientific material as soon as possible after acceptance. "Just Accepted" manuscripts appear in full in PDF format accompanied by an HTML abstract. "Just Accepted" manuscripts have been fully peer reviewed, but should not be considered the official version of record. They are citable by the Digital Object Identifier (DOI®). "Just Accepted" is an optional service offered to authors. Therefore, the "Just Accepted" Web site may not include all articles that will be published in the journal. After a manuscript is technically edited and formatted, it will be removed from the "Just Accepted" Web site and published as an ASAP article. Note that technical editing may introduce minor changes to the manuscript text and/or graphics which could affect content, and all legal disclaimers and ethical guidelines that apply to the journal pertain. ACS cannot be held responsible for errors or consequences arising from the use of information contained in these "Just Accepted" manuscripts. 


\title{
Monitoring of CO Binding Sites on Stepped Pt Single Crystal Electrodes in Alkaline Solutions by in situ FTIR Spectroscopy
}

\author{
Manuel J. S. Farias*,†, Carlos Busó-Rogero ${ }^{\ddagger, \S}$, Auro A. Tanaka ${ }^{\dagger}$, Enrique Herrero ${ }^{\ddagger}$ and Juan M. \\ Feliu $^{\ddagger}$ \\ † Departamento de Química, Universidade Federal do Maranhão, Avenida dos Portugueses, \\ 1966 - CEP 65080-805, São Luís - Maranhão, Brazil \\ ${ }^{\ddagger}$ Instituto de Electroquímica, Universidad de Alicante, Ap. 99, E-03080, Alicante, Spain
}

\begin{abstract}
The site geometry preference of CO binding on stepped Pt single crystals in alkaline solution was investigated by in situ FTIR spectroscopy. The surfaces of the Pt single crystals consisted of different width (111) terraces, interrupted by (110) or (100) monoatomic steps. Experiments carried out with $\mathrm{CO}$ adsorbed exclusively on the top of the steps revealed that only linearly bonded CO formed on the (110) steps, while two CO binding geometries (linear and bridge) were observed on the (100) steps. On one hand, for CO adsorbed only on the steps, the positions of the bands corresponding to linearly bonded CO were similar, regardless of the density of steps, suggesting the existence of an interaction between $\mathrm{CO}_{\mathrm{ads}}$ only along the line of the steps. On the other hand, for full CO coverage, the CO stretching frequencies and the geometry of bound CO were sensitive to the width of the (111) terraces and the step orientations. Consequently, the CO binding sites favored linearly bonded CO for surfaces consisting of shorter (111) terraces and (110) steps. Bridge-bonded CO was favored on surfaces consisting of shorter (111) terraces interrupted by (100) steps. In order to understand the origin of the preference of $\mathrm{CO}$ binding sites, the results were compared to the corresponding behavior in acid media, which revealed that in addition to the effect inherent to the Pt surface, the charge on the metal side in an aqueous environment should be taken into consideration. The analysis suggested that the $\mathrm{CO}$ adlayers formed at full coverage in acidic and alkaline media had different structures. On the other hand, the structure of the layer of CO adsorbed only at steps was independent of $\mathrm{pH}$.
\end{abstract}

Keywords: Electrocatalysis; alkaline media; CO adsorption; Pt surface; site-specific.

§Present address: Instituto Madrileño de Estudios Avanzados Nanociencia, c./Faraday 9, Campus Universitario de Cantoblanco, E-28049 Madrid, Spain

*Corresponding author: manueljsfarias@gmail.com

(Manuel J. S. Farias). Phone: +55 9833018246 


\section{Introduction}

The electrochemical behavior of the $\mathrm{Pt} / \mathrm{CO}$ system has received a great deal of attention during the last five decades, by numerous researchers worldwide. ${ }^{1-25}$ The adsorption and oxidation reaction of $\mathrm{CO}$ serves as a testing reaction in surface electrochemistry and electrocatalysis, with many insights in the field of electrocatalysis, especially those concerning the assignment of active sites, having been obtained by employing the $\mathrm{Pt} / \mathrm{CO}$ system as a model. ${ }^{26-28}$ However, the vast majority of studies of the adsorption and oxidation of CO on model stepped Pt surfaces have been conducted using acid media. In particular, the application of spectro-electrochemical techniques to study the $\mathrm{Pt}(h \mathrm{kl}) / \mathrm{CO}$ system using stepped Pt single crystals in alkaline media has received little attention. Only one paper was found on this subject. ${ }^{29}$ This lack of attention may be neglecting important phenomena that occurs in the $\mathrm{Pt}(h k l) / \mathrm{CO}$ system under alkaline conditions, which may differ from those observed in acid media. This is supported by studies of the $\mathrm{Pt}_{\text {poly }} / \mathrm{CO}$ system using infrared reflection-absorption spectroscopy, ${ }^{30-31}$ which have shown that there are major changes when passing from low to high $\mathrm{pH}$ solutions. These changes not only concern the positions of the vibrational frequencies of the $\mathrm{CO}_{\mathrm{ads}}$ bands, but also the ratios of (or compositions) of the different binding geometry of $\mathrm{CO}_{\mathrm{ads}}$, such as the bridge $\left(\mathrm{CO}^{\mathrm{B}}\right)$ and linearly bonded $\mathrm{CO}\left(\mathrm{CO}^{\mathrm{L}}\right)$. A more controlled way to understand the origins of these changes occurring on $\mathrm{Pt}_{\text {poly }} / \mathrm{CO}$ system, when changing the solution $\mathrm{pH}$, is to conduct similar studies employing stepped crystalline surfaces, because the preference for $\mathrm{CO}$ binding sites could, in principle, be related to the surface structure. The stepped surfaces constitute a class of crystalline solid surfaces in which the top layer of the atoms (those on the surface) presents, in a regular pattern, more than one type of geometric configuration, such as terraces and steps. On these surfaces, it has been observed that the heat of adsorption of $\mathrm{CO}$ varies over the surface, with sites presenting low coordination atoms (such as those associated with steps, kinks, and ad-atoms) having higher heats of adsorption, compared to sites with high coordination atoms (such as those on terraces). ${ }^{32}$ Also, the adsorption energies predicted by DFT for the step sites are higher than those from the terrace. ${ }^{33-34}$ This provides the opportunity to study the influence that the surface structure has on spectroscopic changes of the Pt/CO system in alkaline media, hence enabling comparison with the behavior in acidic media.

Given the importance of this subject for electrocatalysis, as outlined above, there have been efforts to understand the CO super-structure on Pt single crystals employing surface 
probe techniques. For the $\mathrm{Pt}(111)$ surface in an acid medium, ${ }^{7}$ in the presence of CO-saturated solution and at a potential of $0.06 \mathrm{~V}_{\mathrm{RHE}}$, in situ STM imaging revealed a $p(2 \times 2)-3 \mathrm{CO}$ (unit cell) superstructure (with $\theta_{\mathrm{CO}} \simeq 0.75$ ), consisting of 1 tilted $\mathrm{CO}^{\mathrm{L}}$ (linearly bonded $\mathrm{CO}$ ) and $2 \mathrm{CO}^{\mathrm{M}}$ (3-fold bonded CO). At the same potential, in situ FTIR spectroscopy analysis revealed band intensities equivalent to a $\mathrm{CO}^{\mathrm{L}}: \mathrm{CO}^{\mathrm{M}}$ ratio of 2:1 for these two $\mathrm{CO}$ binding geometries. In the presence of traces of $\mathrm{CO}$ in solution (very low partial pressure), at a potential of $0.4 \mathrm{~V}_{\mathrm{RHE}}$, the $(\sqrt{ } 19 \times \sqrt{ } 19) R 23.4^{\circ}-13 \mathrm{CO}$ (unit cell) superstructure $\left(\theta_{\mathrm{CO}} \simeq 0.68\right)$ was found. ${ }^{7}$ The $(\sqrt{19} \times \sqrt{19}) R 23.4^{\circ}-13 \mathrm{CO}$ superstructure consisted of 1 tilted $\mathrm{CO}^{\mathrm{L}}, 6$ near (tilted) $\mathrm{CO}^{\mathrm{L}}$, and 6 near $\mathrm{CO}^{\mathrm{B}}$ (near bridge-bonded $\mathrm{CO}$ ), with higher band intensity for $\mathrm{CO}^{\mathrm{L}}$. A similar structure was found by Tolmachev et al., ${ }^{35}$ at a potential of around $0.6 \mathrm{~V}_{\mathrm{RHE}}$. On $\operatorname{Pt}(100)-(1 \times 1)$ in acid solution, at a potential of $0.1 \mathrm{~V}_{\mathrm{RHE}}$, Watanabe et al. ${ }^{36}$ proposed the existence of a $c(6 \times 2)-10 \mathrm{CO}$ (unit cell) structure $\left(\theta_{\mathrm{CO}} \simeq 0.83\right.$ ), consisting of linearly and bridge-bonded $\mathrm{CO}$ at a ratio of $3: 2$ (considering the total CO). In general terms, the preference for the geometry of CO binding depends on the surface structure and CO coverage. The potential and/or the charge on the metal also influence the geometry of $\mathrm{CO}$ binding, with low coordinated $\mathrm{CO}$ being preferred at more positive electrode potential. ${ }^{37-38}$ In an alkaline medium, the superstructures of the compressed CO layer are not yet as well characterized as they are in an acidic medium, for $\mathrm{Pt}$ basal planes (and some stepped surfaces). The presence of those compressed CO superstructures requires the existence of a long-range substrate structure, ${ }^{39}$ which means that such CO superstructures may not be found on stepped Pt surfaces with short (111) terraces. As an approximation, the position of the band can be related to $\mathrm{CO}$ binding sites, while the band intensity is related to the coverage of $\mathrm{CO}$ on the binding sites.

For a compressed CO adlayer, reasons for the discrepancy between $\mathrm{CO}$ coverage on the binding sites and the band intensities (as noted above) include the dipole-dipole coupling between adsorbed $\mathrm{CO}$ molecules. ${ }^{40}$ For the $\mathrm{Pt}(111)$ basal plane in acid solution ${ }^{7}$ and in alkaline media, ${ }^{41}$ the spectra for full CO coverage present many bands, indicating the coexistence of a multitude of different forms of $\mathrm{CO}$ binding sites, such as linear, bridging, and three-fold sites. The vibrational features of a CO adlayer can be characterized as coupled oscillators. ${ }^{42-44}$ Coupling between dipoles causes transfer of the band intensity to the highest frequency band at the expense of the intensity of the band at lower frequency, which can result in an undetectable band in the spectra for the lower frequency. ${ }^{42}$ In the case of surfaces with heterogeneous sites, such as stepped surfaces, the complexity of the $\mathrm{Pt} / \mathrm{CO}$ systems increases 
further, because the vibrational frequencies of the CO adsorbed on (111) terraces (characterized by frequencies of high wavenumber) and the $\mathrm{CO}$ at steps/defects (characterized by frequencies of low wavenumber) are strongly coupled. ${ }^{45}$ However, there is an opportunity to simplify the Pt/CO systems in the case of stepped single crystal surfaces. Ideally, it should be possible to observe the vibrational frequencies of $\mathrm{CO}_{\mathrm{ads}}$ on the steps/defects, free from the interference of $\mathrm{CO}_{\mathrm{ads}}$ on terrace sites. To this end, starting from full $\mathrm{CO}$ coverage on a stepped Pt surface, it is possible to achieve a condition in which only the top of the (110) or (100) step sites are occupied by adsorbed $\mathrm{CO} .{ }^{46-47}$ In this sense, experiments can be performed for $\mathrm{CO}$ under different regimes of surface coverage, considering full CO coverage and CO only on steps.

In this work, in situ FTIR spectroscopy was used to investigate $\mathrm{CO}_{\mathrm{ads}}$ on specific sites of $\mathrm{Pt}$ in alkaline solution. The surfaces employed consisted of (111) terraces interrupted by (110) or (100) monoatomic steps. Changes in the CO binding site populations were detected, depending on the step orientation and the width of the (111) terraces. The results obtained in alkaline media (high $\mathrm{pH}$ ) were compared to those obtained in acid solutions (low $\mathrm{pH}$ ).

\section{Experimental Section}

\subsection{Electrodes and Control of Potential}

In this work, platinum surfaces vicinal to the (111) pole were employed as the working electrode. The surfaces of these single crystals consisted of (111) terraces interrupted by (110) or (100) monoatomic steps. According to Lang-Joyner-Somorjai, ${ }^{48}$ surfaces consisting of (111) terraces and (110) monoatomic steps belong to the $\operatorname{Pt}(\mathrm{s})-[(n-1)(111) \times(110)]$ series, with the Miller index being ( $n, n, n-2)$. Surfaces consisting of (111) terraces interrupted by (100) monoatomic steps belong to the $\operatorname{Pt}(\mathrm{s})-[n(111) \times(100)]$ series, with Miller index of $\left(n+1, n-1, n^{-}\right.$ 1). The terms $n-1$ or $n$ refer to the number of platinum atom rows at the (111) terraces parallel to the (110) or (100) steps, respectively. The individual surfaces used in this work were as follows:

$$
\begin{gathered}
\operatorname{Pt}(171715) \equiv \operatorname{Pt}(\mathrm{s})-[16(111) \times(110)], n-1=16 \\
\operatorname{Pt}(171515) \equiv \operatorname{Pt}(\mathrm{s})-[16(111) \times(100)], n=16 \\
\operatorname{Pt}(332) \equiv \operatorname{Pt}(\mathrm{s})-[5(111) \times(110)], n-1=5 \\
\operatorname{Pt}(322) \equiv \operatorname{Pt}(\mathrm{s})-[5(111) \times(100)], n=5 \\
\operatorname{Pt}(331) \equiv \operatorname{Pt}(\mathrm{s})-[2(111) \times(110)], n-1=2
\end{gathered}
$$




\subsection{Electrolyte and Reagents}

The experiments were performed in a solution of $0.1 \mathrm{M} \mathrm{NaOH}$ (Merck KGaA, 99.99\%) prepared in ultrapure water $(18.2 \mathrm{M} \Omega \mathrm{cm})$. For degassing the solutions, Ar (N50, Alpha Gaz) was used. The CO gas used was type N47 (Alpha Gaz).

\subsection{Adsorption of CO on Stepped Pt Single Crystal Surfaces}

For all experiments, the $\mathrm{CO}$ gas was bubbled through the solution for $5 \mathrm{~min}$ at a dosing potential of $0.100 \mathrm{~V}_{\mathrm{RHE}}$. Using a spectro-electrochemical cell similar to the one described elsewhere, ${ }^{51}$ the oriented face of the electrode was immersed in the solution, followed by bubbling CO gas for $5 \mathrm{~min}$. In order to confirm blockage of the surface of the electrode, the potential was scanned from $0.100 \mathrm{~V}_{\mathrm{RHE}}$ up to ca. $0.2 \mathrm{~V}_{\mathrm{RHE}}$ and then back to $0.05 \mathrm{~V}_{\mathrm{RHE}}$, at a rate of $0.05 \mathrm{~V} \mathrm{~s}^{-1}$. Next, for removal of the non-adsorbed CO, the potential was set at $0.100 \mathrm{~V}_{\mathrm{RHE}}$ (the dosing potential) and Ar was bubbled through the solution for $18 \mathrm{~min}$. After this, the $\mathrm{Pt} / \mathrm{CO}$ systems was prepared for examination using in situ FTIR spectroscopy.

In order to obtain a $\mathrm{CO}$ coverage condition in which $\mathrm{CO}$ was adsorbed exclusively on the steps (with CO only on the top side of the steps), a full CO adlayer was partially oxidized 
in a controlled voltammetric experiment. It is important to point out that in order to carry out these experiments each type of Pt surface required a specific potential programming, with the upper potential being specific for each surface in each stage of CO coverage. When the potential limit $\left(E^{+}\right)$was reached in the voltammetric scanning, the potential was stepped back to $0.100 \mathrm{~V}$, after which the potential was scanned only in the hydrogen region. Similar experiments, using successive voltammetric cycles to obtain CO only on the top of the steps, were described elsewhere. ${ }^{46,52}$ Since the voltammetric features of the hydrogen region of the Pt stepped surface allows to distinguish the signals from the adsorbed hydrogen on the terrace and step sites, ${ }^{53}$ scanning the potential in the hydrogen region enabled diagnosis of the types of sites that were released after each partial $\mathrm{CO}_{\mathrm{ads}}$ oxidation cycle. The electrode was ready for in situ FTIR spectroscopy monitoring when the signal from hydrogen adsorbed on the terrace was completely restored while maintaining that corresponding to the adsorption of hydrogen on the step fully blocked.

\subsection{In situ FTIR Experiments}

The spectro-electrochemical experiments were performed using a Nicolet (Model 8700) spectrometer equipped with an MCT detector. The spectra were obtained as the average of 100 interferograms, at a resolution of $8 \mathrm{~cm}^{-1}$, using potentials ranging from 0.050 to 0.400 $\mathrm{V}_{\mathrm{RHE}}$, with an interval of $25 \mathrm{mV}$. After recording the spectrum at $0.400 \mathrm{~V}_{\mathrm{RHE}}$, the potential was stepped to $0.900 \mathrm{~V}_{\mathrm{RHE}}$, at which $\mathrm{CO}$ is fully oxidized from the surface. At this potential, a single spectrum was recorded for use as the reference spectrum. The radiation employed was $p$-polarized, enabling the detection of active species both on the electrode surface and in solution, according to the surface selection rule. ${ }^{51}$ All the spectra in this paper were given in absorbance units, as follows:

$$
A=-\log \left(\frac{R_{0}-R_{S}}{R_{0}}\right) \text { versus } v / \mathrm{cm}^{-1}
$$

where $R_{0}$ is the single beam reflectance reference spectrum at potential of $0.900 \mathrm{~V}$ and $R_{S}$ is the single beam reflectance spectrum at the sampling potential.

\section{Results}

$\mathrm{CO}_{\text {ads }}$ spectra were acquired for the different stepped Pt crystal surfaces with different widths of the (111) terraces. In order to provide a better analysis of the results, surfaces with 
the same terrace width but different step geometry will be compared. Surface characterization by voltammetry will be presented first.

\subsection{Blank Cyclic Voltammetry and Surface Site Assignment}

Figure 1 shows two representative blank cyclic voltammograms for the $\operatorname{Pt}(\mathrm{s})-[(n-$ $1)(111) \times(110)]$ and $\operatorname{Pt}(\mathrm{s})-[n(111) \times(100)]$ series, namely $\operatorname{Pt}(171715)$ with $n-1=16$ and (110) steps, and $n=16$ and (100) steps, respectively. It should be highlighted that the profile of each cyclic voltammogram indicated that the surface was well-ordered and that the solution was free from impurities. For the voltammetry of the (111) terraced surfaces, the hydrogen region profile (potentials below $\sim 0.4 \mathrm{~V}_{\mathrm{RHE}}$ ) could be used to distinguish one kind of stepped surface from another, depending on the type of sites (110) or (100) present. In this way, for the $\mathrm{Pt}(17$ 17 15) surface, the voltammetric profile presented a pair of peaks at $\sim 0.25 \mathrm{~V}_{\mathrm{RHE}}$, due to the (reversible) discharge of the proton to form the adsorbed hydrogen at the (110) steps. In the case of the $\operatorname{Pt}(1715$ 15) surface, which presents (100) step orientations, the peaks due to hydrogen adsorption/desorption occurred at $\sim 0.38 \mathrm{~V}_{\mathrm{RHE}}$. The reversible processes occurring at around $\sim 0.77$ VRHE were related to the participation of oxygen-containing species on the (111) terraces. $^{54}$

\subsection{In situ FTIR Spectra of CO on Pt(17 17 15) and Pt(17 15 15) Surfaces}

As aforementioned, $\operatorname{Pt}(1717$ 15) and $\operatorname{Pt}(1715$ 15) surfaces possess (111) terraces with the same terrace width (16 atomic rows), but differ in terms of the step orientations, with (110) and (100) orientations for $\operatorname{Pt}(1717$ 15) and $\operatorname{Pt}(1715$ 15), respectively. Figure 2A shows a series of spectra for full CO coverage on a $\mathrm{Pt}(1717$ 15) surface. Considering the spectrum at $0.100 \mathrm{~V}_{\mathrm{RHE}}$, the band maximum was centered at $2017 \mathrm{~cm}^{-1}$ and can be attributed to the stretching frequencies of linearly bonded CO on both (111) terrace and (110) step sites. The position of the band is potential-dependent, with $\mathrm{dv}_{\mathrm{CO}^{L}} / \mathrm{d} E \simeq 47 \mathrm{~cm}^{-1} \mathrm{~V}^{-1}$ (Stark tuning slope) between 0.05 and $0.3 \mathrm{~V}_{\mathrm{RHE}}$. For $\mathrm{Pt}(111)$ in the presence of $0.1 \mathrm{M} \mathrm{NaOH}$ solution and with full CO coverage, García et al. ${ }^{41}$ found $\mathrm{dv}_{\mathrm{CO}^{2}} / \mathrm{d} E=37 \mathrm{~cm}^{-1} \mathrm{~V}^{-1}\left(\sim 0.05<E<0.15 \mathrm{~V}_{\mathrm{RHE}}\right)$. In acid media, a Stark tuning slope of $\mathrm{dv}_{\mathrm{CO}^{L}} / \mathrm{d} E \simeq 30 \mathrm{~cm}^{-1} \mathrm{~V}^{-1}$ has been reported for linearly bonded $\mathrm{CO}$ at full coverage on $\mathrm{Pt}$ in (of different surface orientation). ${ }^{12,55-56}$ Another band at 1796 $\mathrm{cm}^{-1}$ can be assigned to bridge-bonded CO exclusively on the (111) terraces. The position of this band is potential-dependent, with a slope of around $\sim 80 \mathrm{~cm}^{-1} \mathrm{~V}^{-1}$ (very imprecise) for 
potentials between 0.05 and $0.3 \mathrm{~V}_{\mathrm{RHE}}$. At $0.100 \mathrm{~V}_{\mathrm{RHE}}$, the ratio of the integrated band intensities for the bridge $\mathrm{CO}$ and linear $\mathrm{CO}\left(A_{\left.\mathrm{CO}^{B}: A_{\mathrm{CO}}\right)}\right)$ is around 1:2. It should be noted that this ratio does not reflect the site occupancy of bridge and linearly bonded CO species, because it considers neither the molar absorption coefficient, nor the intensity of band transfer. However, it is possible to compare the $A_{\mathrm{CO}^{B}:} A_{\mathrm{CO}^{L}}$ ratios for full $\mathrm{CO}$ coverage on different stepped surfaces at the same potential, because it can be assumed that these interfering quantities are similar for spectra obtained at the same potential and with similar full $\mathrm{CO}$ coverage. Different $A_{\mathrm{CO}^{B}:} A_{\mathrm{CO}^{L}}$ ratios for different surfaces are, then, indicative of changes in the preference for $\mathrm{CO}$ binding sites. Therefore, the intensities of the integrated bands can be compared. The band due to bridge-bonded $\mathrm{CO}$ is assigned to bridge $\mathrm{CO}$ exclusively on the (111) terraces, because bridge CO was not formed on the (110) steps (as shown subsequently by the experimental results presented in Figure 2B). In the case of the experiment with a full CO adlayer, it is reasonable to suppose that all types of sites (terraces and steps) were occupied by adsorbed CO. All these sites were occupied by $\mathrm{CO}$ in the experiment whose results are shown in Figure 2A. However, inspection of the spectra in Figure 2A revealed no band assigned to linearly bonded CO on the step sites. The complete absence (or invisibility) of the bands for $\mathrm{CO}$ on the step sites was due to the dipole-dipole coupling effect. ${ }^{45}$, 57 The dipoledipole coupling caused band intensity transfer from lower frequency (as for the linearly bonded CO on the steps) to higher frequency (as for the linearly bonded CO on the terraces), ${ }^{45}$ so that bands at lower frequencies (such as the band for $\mathrm{CO}$ on the step sites) became invisible or undetectable in the spectra. In order to overcome this difficulty in detecting the band intensity for the $\mathrm{CO}$ on the steps, experiments were performed in which the $\mathrm{CO}$ molecules were only present on the top side of the (110) steps of the $\operatorname{Pt}(1717$ 15) surface (Figure 2B). For the spectrum at potential of $0.100 \mathrm{~V}_{\mathrm{RHE}}$, a single $\mathrm{CO}$ band was present, centered at $\sim 1964$ $\mathrm{cm}^{-1}$. This band was due to the stretching frequencies of the linearly bonded $\mathrm{CO}$ on the top side of the (110) steps, free from the interference of $\mathrm{CO}_{\mathrm{ads}}$ on (111) terraces. The center of this band was potential dependent, with the frequency of the maximum band shifting at a rate of $\sim 95 \mathrm{~cm}^{-1} \mathrm{~V}^{-1}$ for potentials between 0.05 and $0.3 \mathrm{~V}$. This Stark tuning slope is significantly higher than that for linearly bonded $\mathrm{CO}$ in a full $\mathrm{CO}$ adlayer. It should be highlighted that no bands attributed to bridge-bonded $\mathrm{CO}$ at the (110) steps appeared in these spectra (Figure 2B), indicating that the $\mathrm{CO}$ adsorbed on the (110) steps was exclusively linearly bonded. This result agree with the predicted geometry of adsorbed CO from DFT. ${ }^{33}$ It should be noted that the 
magnitude of the band for adsorbed CO exclusively on the steps presented a relative increase as the potential was increased. The origin of such potential dependence is not well understood and could be due to a change in the configuration of $\mathrm{CO}_{\text {ads }}$ (between possible adsorption modes and/or tilt angle) and the influence of co-adsorbed species. It should be noted that between $\mathrm{CO}$ absorption bands there is a strong energy transfer from those appearing at low wave numbers to those at high weave numbers, which can also affect the band intensity and probably is dependent on the external field. This same trend (dependence of band intensity on the potential) was observed for all experiments in which $\mathrm{CO}$ was only on the step sites.

At a potential of $0.100 \mathrm{~V}_{\mathrm{RHE}}$ (Figure 2), the band corresponding to linearly bonded $\mathrm{CO}$ only on the top side of the (110) steps is shifted by $\sim 53 \mathrm{~cm}^{-1}$ towards lower wavenumber ( $\Delta v$ $=-53 \mathrm{~cm}^{-1}$ ), as compared to the frequency for linearly bonded $\mathrm{CO}$ at full coverage. This confirmed that a major component of the band intensity for linearly bonded CO on (111) terraces was acquired from the $\mathrm{CO}$ adsorbed at the (110) step sites by the mechanism of intensity transfer.

In addition to these bands, a broad and intense band at $\sim 1400 \mathrm{~cm}^{-1}$ is observed in the Figure 2 and attributed to dissolved carbonate, ${ }^{41,58}$ which is the final product of the oxidation of CO in highly alkaline solution $\left(\mathrm{CO}+4 \mathrm{OH}^{-} \rightarrow \mathrm{CO}_{3}^{2-}+2 \mathrm{H}_{2} \mathrm{O}+2 e^{-}\right)$. The carbonate band appeared in the spectra because the reference spectrum was recorded at a potential at which the $\mathrm{CO}_{\text {ads }}$ was fully oxidized, which in the present case was $0.900 \mathrm{~V}_{\mathrm{RHE}}$. For this reason and for easier visualization in Figure 2A, only the frequency range corresponding to the adsorbed CO is shown. In the series of spectra in Figure 2, the broad band at $\sim 1620 \mathrm{~cm}^{-1}$ is attributed to the bending mode of water in a thin layer. ${ }^{51}$

For a full CO adlayer on $\operatorname{Pt}(1715$ 15) (Figure 3A), the spectrum at a potential of 0.100 $\mathrm{V}_{\mathrm{RHE}}$ exhibits bands centered at $\sim 2012 \mathrm{~cm}^{-1}$ (Stark tuning slope of about $\sim 44 \mathrm{~cm}^{-1} \mathrm{~V}^{-1}$ ) and $1805 \mathrm{~cm}^{-1}$ (slope of about $56 \mathrm{~cm}^{-1} \mathrm{~V}^{-1}$ ), attributed to linearly and bridge-bonded CO on (111) terraces and (100) steps, respectively. At $0.100 \mathrm{~V}_{\mathrm{RHE}}$, the $A_{\mathrm{CO}^{B}: A_{\mathrm{CO}}^{L}}$ ratio is ca. 1:1. It should be mentioned that the accuracy of this ratio is lower than that for the previous surface because the bridge $\mathrm{CO}$ band is distorted by the intense band of the $\mathrm{O}-\mathrm{H}$ bending mode of water in a thin layer.

The series of spectra for CO only on the top side of the (100) steps exhibited two bands (Figure 3B). Considering the spectrum at a potential of $0.100 \mathrm{~V}_{\mathrm{RHE}}$, a band at $\sim 1961 \mathrm{~cm}^{-1}$ is due to the stretching frequency of linearly bonded CO, while a band at $\sim 1747 \mathrm{~cm}^{-1}$ (which 
was most discernible at $0.125 \mathrm{~V}$ ) can be attributed to bridge-bonded CO. The presence of bridge-bonded CO on (100) steps represented an important difference, compared to the (110) steps that only presented linearly bonded CO. Different adsorption geometries for the (110) and (100) have been also proposed from DFT results. ${ }^{33}$ The spectra at $0.100 \mathrm{~V}_{\mathrm{RHE}}$ (Figure 3) shows that the bands corresponding to linearly and bridge-bonded CO shift to lower frequencies by about -51 and $-58 \mathrm{~cm}^{-1}$, respectively, compared to the frequencies for similar $\mathrm{CO}$ binding geometries under the condition of full $\mathrm{CO}$ coverage. The shift suggests that bands due to $\mathrm{CO}$ at the (111) terraces gain band intensity from both linearly and bridge-bonded CO on (100) steps. The Stark tuning slopes corresponding to the CO only on (100) steps were $\sim 95$ and $\sim 78 \mathrm{~cm}^{-1} \mathrm{~V}^{-1}$ for linearly and bridge-bonded CO. In other work, Korzeniewski et al. ${ }^{45,57}$ reported a high Stark tuning slope for CO on the (100) steps of a $\operatorname{Pt}(557)$ surface. The reason for this high gradient at low coordinated sites is not yet understood.

\subsection{In situ FTIR Spectra of CO on Pt(332) and Pt(322) Surfaces}

The $\operatorname{Pt}(332)$ and $\operatorname{Pt}(322)$ surfaces consist of 5-atoms-wide (111) terraces, differing in the step orientation, which is (110) for $\operatorname{Pt}(332)$ and (100) for $\operatorname{Pt}(322)$. The spectra for full CO coverage show two $\mathrm{CO}$ bands. Considering the spectrum at a potential of $0.100 \mathrm{~V}_{\mathrm{RHE}}$ for full CO coverage on $\operatorname{Pt}(332)$ (Figure 4A), the bands at $\sim 2016 \mathrm{~cm}^{-1}$ (slope of $\mathrm{d} v_{\mathrm{CO}} / \mathrm{d} E \simeq 48 \mathrm{~cm}^{-1}$ $\mathrm{V}^{-1}$ ) and $1817 \mathrm{~cm}^{-1}$ are due to the linearly and bridge-bonded CO, respectively. The ratio of the integrated band intensity of bridge $\mathrm{CO}$ to that of linear $\mathrm{CO}\left(A_{\mathrm{CO}^{B}: A_{\mathrm{CO}} L}\right)$ was $1: 3.2$. On the other hand, the spectra recorded for CO only on the top side of the (110) steps are shown in Figure 4B. In this Figure 4B, the spectrum at $0.100 \mathrm{~V}_{\mathrm{RHE}}$ showed the band at $1962 \mathrm{~cm}^{-1}$ due to linearly bonded CO, representing a red-shift of $-54 \mathrm{~cm}^{-1}$, compared to the position of the band for linearly bonded $\mathrm{CO}$ under the condition of full $\mathrm{CO}$ coverage. The potential dependence of the band for CO only on the top side of the (110) steps presents a rate (Stark tuning slope) of $78 \mathrm{~cm}^{-1} \mathrm{~V}^{-1}$.

Figure 5 presents the series of spectra for the $\mathrm{Pt}(322) / \mathrm{CO}$ system. At full CO coverage, the spectrum at $0.100 \mathrm{~V}_{\mathrm{RHE}}$ shows a band centered at $\sim 2008 \mathrm{~cm}^{-1}$ (with $\mathrm{du}_{\mathrm{CO}^{L}} / \mathrm{d} E \simeq 45 \mathrm{~cm}^{-1} \mathrm{~V}^{-}$ ${ }^{1}$ ), due to the stretching frequencies of linearly bonded CO on both (111) terraces and (100) steps. The band centered at $\sim 1819 \mathrm{~cm}^{-1}$ indicated the presence of bridge-bonded CO on both (111) terraces and (100) steps. The $A_{\mathrm{CO}^{B}: A_{\mathrm{CO}}{ }^{L}}$ ratios for these bands were $\sim 1: 1$. Due to the difficulties in obtaining CO only on the steps of this surface, experiments are only shown for 
complete CO coverage. A Stark tuning slope of $\sim 75 \mathrm{~cm}^{-1} \mathrm{~V}^{-1}$ was obtained for linearly bonded $\mathrm{CO}$. The slope for bridge $\mathrm{CO}$ is quite imprecise.

\subsection{In situ FTIR Spectra of CO on Pt(331) and Pt(311) Surfaces}

The $\operatorname{Pt}(331)$ and $\operatorname{Pt}(311)$ surfaces have the shortest (111) terraces used in this work, with widths of 2 atoms. The orientations of the monoatomic steps on $\operatorname{Pt}(331)$ and $\operatorname{Pt}(311)$ surfaces are (110) and (100), respectively. Only results for full CO coverage are presented here, since obtaining the specific coverage condition of CO only on the top of the steps of these surfaces is very difficult, even in alkaline media. Figure 6A presents the series of spectra for the $\mathrm{Pt}(331) / \mathrm{CO}$ system. In the spectrum acquired at $0.100 \mathrm{~V}_{\mathrm{RHE}}$, the dominant band at $\sim 2036 \mathrm{~cm}^{-1}$ (slope of $\mathrm{d}_{\mathrm{CO}^{L}} / \mathrm{d} E \simeq 45 \mathrm{~cm}^{-1} \mathrm{~V}^{-1}$ ) was due to the stretching frequencies of linearly bonded CO on both (111) terraces and (110) steps. A smaller band due to bridge-bonded CO

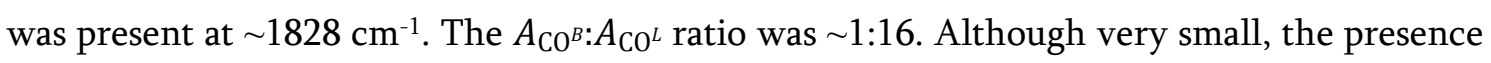
of the band for bridge $\mathrm{CO}$ on the $\mathrm{Pt}(331)$ surface was an important finding, because this band is not found in the spectra for $\mathrm{Pt}(331) / \mathrm{CO}$ in acid media, as reported by Rodes et al. ${ }^{39}$ and Hoshi et al.. ${ }^{59}$

The $\mathrm{Pt}(311) / C O$ system showed an opposite trend to that of the $\mathrm{Pt}(331) / \mathrm{CO}$ system. For example, in the spectrum acquired at $0.100 \mathrm{~V}_{\mathrm{RHE}}$ (Figure 6B), the dominant band at $\sim 1842$ $\mathrm{cm}^{-1}$ was due to bridge-bonded CO. A smaller band due to linearly bonded CO was present at $\sim 1980 \mathrm{~cm}^{-1}$. The $A_{\mathrm{CO}^{B}}: A_{\mathrm{CO}^{L}}$ ratio was $\sim 2.3: 1$. Table 1 presents a summary of all these data. Considering the structure of the surface, it was previously observed that on (100) facets in alkaline solution $(0.1 \mathrm{M} \mathrm{NaOH}),{ }^{29,60}$ bridge-bonded $\mathrm{CO}$ dominates on a $\mathrm{Pt}(100)$ basal plane.

\subsection{In situ FTIR Spectra of CO on a Pt(531) Surface}

The $\mathrm{Pt}(531)$ surface possesses short (111) terraces that are 3 atoms wide. It also presents sites with both (110) and (100) configurations. The series of spectra recorded for full CO coverage on a $\operatorname{Pt}(531)$ surface is shown in Figure 7. The spectra presented bands due to both linearly bonded CO (centered at $\sim 2004 \mathrm{~cm}^{-1}$, at a potential of $0.100 \mathrm{~V}_{\mathrm{RHE}}$ ) and bridge-bonded $\mathrm{CO}$ (centered at $\sim 1780 \mathrm{~cm}^{-1}$, at a potential of $0.100 \mathrm{~V}_{\mathrm{RHE}}$ ). The Stark tuning slopes were $\mathrm{dv}_{\mathrm{CO}^{L}} /$ $\mathrm{d} E \simeq 68 \mathrm{~cm}^{-1} \mathrm{~V}^{-1}$ for linearly bonded $\mathrm{CO}$ and $\mathrm{dv}_{\mathrm{CO}^{B}} / \mathrm{d} E \simeq 42 \mathrm{~cm}^{-1} \mathrm{~V}^{-1}$ for bridge-bonded CO.

\section{Discussion}


The results clearly showed that the presence of crystalline steps on (111) planes influenced the stretching frequencies of the bands for the linearly and bridge-bonded CO, under the condition of full CO coverage. The comparison of the relative magnitudes of these bands also revealed that the preference for CO binding sites was strongly influenced by the surface structure. These data will be discussed in comparison with the results obtained using

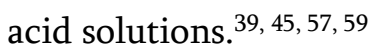

\subsection{Effect of the Structure of the Surfaces on Stretching Frequencies of $\mathrm{CO}_{a d s}$}

The experiments with CO only on the top of the steps enabled the evaluation of the stretching frequencies of $\mathrm{CO}$ at the steps, free from interference due to $\mathrm{CO}$ on terraces. An initial consideration is that the density of the (110) steps on $\mathrm{Pt}(332)$ surface is higher than on $\operatorname{Pt}(1717$ 15) surface. The (111) terraces of $\operatorname{Pt}(1717$ 15) and $\operatorname{Pt}(332)$ have nominal widths of 16 and 5 atoms, respectively. Consequently, the total CO coverage on the top of the (110) steps of the $\mathrm{Pt}(332)$ surface is higher than the total amount of CO on the top of the (110) steps of the $\mathrm{Pt}(1717$ 15) surface. Despite the difference in total CO coverage on the steps (of each surface), the set of spectra in Figures 2A and 3B show that the maxima of the bands for linearly bonded CO on the steps appeared at the same position. For example, for CO only on the top of the (110) steps of $\operatorname{Pt}\left(\begin{array}{lll}17 & 17 & 15\end{array}\right)$ and $\operatorname{Pt}(332)$ surfaces, at a potential of $0.100 \mathrm{~V}_{\mathrm{RHE}}$, the maximum band for linearly bonded CO was centered at $v_{\mathrm{CO}^{L}} \simeq 1963 \mathrm{~cm}^{-1}$, regardless of the width of the (111) terraces (see Table 1). Therefore, based on the density of the (110) steps, with the $\mathrm{Pt}(332)$ surface having an approximately three-fold higher step density, the total amount of CO only on the top of the (110) steps was greater for $\operatorname{Pt}(332)$ than for the $\operatorname{Pt}(1717$ 15) surface. However, despite this difference in step density and, consequently, the total CO coverage on step sites, the position of the $\mathrm{CO}_{\text {ads }}$ band was hardly affected by the step density. Under the condition of CO only on the top of the steps, the lack of dependence of the band position on the density of steps (occupied by $\mathrm{CO}$ ) therefore indicated an absence of interaction between $\mathrm{CO}_{\mathrm{ads}}$ molecules on the neighboring rows of the (110) steps, even for surfaces with narrow terraces. Hence, the intra-molecular coupling was restricted only to $\mathrm{CO}_{\mathrm{ads}}$ along the line of steps, so dipole-dipole coupling was confined along one dimension, with little influence on the $\mathrm{CO}$ band position. This almost unchanged band position for $\mathrm{CO}$ on the steps indicated that the experimental strategy consisting of partial stripping of a $\mathrm{CO}$ adlayer was very successful for obtaining CO only on the top of the steps. 
At full CO coverage, the stretching frequencies are strongly influenced by the structure of the surface. For stepped $\operatorname{Pt}$ surfaces of the $\operatorname{Pt}(s)-[(n-1)(111) \times(110)]$ series, such as $\operatorname{Pt}(1717$ 15), $\operatorname{Pt}(332)$, and $\operatorname{Pt}(331)$, the position of the band for linearly bonded $\mathrm{CO}\left(\mathrm{v}_{\mathrm{CO}}{ }^{L}\right)$ was shifted to higher values as the (111) terraces become shorter. In quantitative terms, there was a shift of around $+19 \mathrm{~cm}^{-1}$ in $\mathrm{v}_{\mathrm{CO}^{L}}$ when passing from $\operatorname{Pt}(1717$ 15) to $\operatorname{Pt}(331)$. Similar behavior was observed for the band corresponding to bridge-bonded $\mathrm{CO}\left(\mathrm{v}_{\mathrm{CO}^{B}}\right)$, which shifted by about +32 $\mathrm{cm}^{-1}$ when passing from $\operatorname{Pt}(1717$ 15) to $\mathrm{Pt}(331)$. In the case of the surfaces of the $\mathrm{Pt}(\mathrm{s})-$ $[n(111) \times(100)]$ series, including $\operatorname{Pt}(171515), \operatorname{Pt}(322)$, and $\operatorname{Pt}(311)$, the position of $\mathrm{v}_{\mathrm{CO}^{B}}$ presented a blue-shift of about $+38 \mathrm{~cm}^{-1}$ when passing from $\operatorname{Pt}\left(1715\right.$ 15) to $\mathrm{Pt}(311)$; while $\mathrm{v}_{\mathrm{CO}^{L}}$ had a negative shift about $-32 \mathrm{~cm}^{-1}$ (Table 1$)$. Under the condition of full CO coverage, $\mathrm{v}_{\mathrm{CO}^{L}}$ was dominated by $\mathrm{CO}$ on terraces, ${ }^{45,61-62}$ indicating that the change in $\mathrm{v}_{\mathrm{CO}}{ }^{L}$ was probably due to the influence of the steps over the terraces. As discussed above, the position of the band for $\mathrm{CO}_{\mathrm{ads}}$ only on the top side of the steps was independent of the defect density. Therefore, for the case of full CO coverage (which presumable all kind of sites were occupied), the steps on the surface greatly modified the physical properties of the terraces, with effects such as alteration of the stretching frequencies for $\mathrm{CO}_{\mathrm{ads}}$ on the (111) terraces. In a work, ${ }^{46}$ based on the sequence in which CO filled the sites on stepped surfaces and the sequence in which the sites were released due to oxidation of this $\mathrm{CO}$, the impact of the defects on terraces was interpreted as the steps giving rise to an energy gradient along the terraces. The present results obtained by spectroscopy are in line with the previous findings since the energy gradient will be steppers as the terrace becomes narrower, altering the bonding of $\mathrm{CO}$ with the surface and therefore, the IR frequencies.

\subsection{Effect of the Solution $\mathrm{pH}$ on Stretching Frequencies of $\mathrm{CO}_{\mathrm{ads}}$}

The Stark tuning slope reflects the effect of the field (and consequently charge and electrode potential) on the frequencies of the different vibrational modes. When changing the potential, the field in the interphase changes, so that the vibrational frequencies of the adsorbed molecules are affected, as observed in Figures 2-5. If the comparison is made between solutions of different $\mathrm{pH}$, potentials have to be transformed to a $\mathrm{pH}$ independent scale, i.e., to the SHE (Standard Hydrogen Electrode), because it will reflect the changes in the surface charge, and therefore the electric field. It should be noted that for $\operatorname{Pt}(111)$, the potential of zero free charge, that is, the potential at which the surface has no charge, and 
therefore, the electric field on the interphase is zero, is constant in the SHE scale with a value of $0.28 \mathrm{~V}_{\mathrm{SHE}}{ }^{63}$ Thus, if the vibrational frequencies of adsorbed $\mathrm{CO}$ at $0.100 \mathrm{~V}_{\mathrm{RHE}}$ in $0.1 \mathrm{M}$ $\mathrm{HClO}_{4}(\mathrm{pH} \simeq 1.2)$ and $0.1 \mathrm{NaOH}(\mathrm{pH} \simeq 12.6)$ have to be compared, the electrode potential has to be transformed from the RHE to the SHE scale. Thus, $0.100 \mathrm{~V}_{\mathrm{RHE}}$ corresponds to +0.03 $\mathrm{V}_{\mathrm{SHE}}$ in $0.1 \mathrm{M} \mathrm{HClO}_{4}$ and to $-0.65 \mathrm{~V}_{\mathrm{SHE}}$ in $0.1 \mathrm{M} \mathrm{NaOH}$, indicating that as the $\mathrm{pH}$ increases the electric field in the interphase is more negative for a constant value of a potential in the RHE scale.

The first difference between the results in acidic and alkaline solutions is the different Stark tuning slope. For full $\mathrm{CO}$ coverage on a $\mathrm{Pt}(111)$ electrode in $0.1 \mathrm{M} \mathrm{NaOH}$ solution, García et al. ${ }^{41}$ found $\mathrm{dv}_{\mathrm{CO}^{L}} / \mathrm{d} E=37 \mathrm{~cm}^{-1} \mathrm{~V}^{-1}\left(\sim 0.05<E<0.15 \mathrm{~V}_{\mathrm{RHE}}\right)$, which was higher than $\mathrm{dv}_{\mathrm{CO}^{L}} / \mathrm{d} E \simeq 30 \mathrm{~cm}^{-1} \mathrm{~V}^{-1}$ for Pt (with different surface orientations) in acid solution. ${ }^{12,55-56} \mathrm{In}$ the present work, $\mathrm{dv}_{\mathrm{CO}} / \mathrm{d} E \simeq 47 \mathrm{~cm}^{-1} \mathrm{~V}^{-1}$ was obtained, regardless of the surface orientation of the Pt crystal. It could be concluded from these results that $d v_{C 0} L / d E$ is always higher in alkaline medium than in acid medium. This increase in the Stark tuning slope as the $\mathrm{pH}$ became higher (with the electric field consequently becoming more negative) could have been due to the effect of the field on the vibrational frequencies, since DFT calculations predict a small increase of the Stark Tuning slope as the field becomes more negative. ${ }^{64-66}$ As pointed out by Weaver et al. ${ }^{67-68}$, in a non-aqueous electrolyte, which allows accessible negative low surface potentials, $\mathrm{dv}_{\mathrm{CO}^{L}} / \mathrm{d} E$ and the $\mathrm{CO}$ binding sites are not entirely consistent with the results obtained in an aqueous electrolyte, which suggests that other factors may be present that influence $d v_{C O} L / d E$ and the CO binding sites. When the Stark tuning slope is calculated using the frequencies at $0.100 \mathrm{~V}_{\mathrm{RHE}}$ at these two $\mathrm{pH}$ values, it is clear that an additional effect is affecting the frequencies. Considering the results obtained using acidic solution $\left(0.1 \mathrm{M} \mathrm{HClO}_{4}\right){ }^{39}$ and alkaline solution $(0.1 \mathrm{M} \mathrm{NaOH})$, with full CO coverage (in the absence of solution CO) on a $\operatorname{Pt}\left(1717\right.$ 15) electrode, the values of $\mathrm{v}_{\mathrm{CO}^{L}}$ are $2061 \mathrm{~cm}^{-1}$ and 2017 $\mathrm{cm}^{-1}$, respectively. These values and the respective absolute potentials allow calculating a Stark tuning slope, according to:

$$
\frac{\Delta \mathrm{v}_{\mathrm{CO}}^{L}}{\Delta E} \simeq \frac{2061 \mathrm{~cm}^{-1}-2017 \mathrm{~cm}^{-1}}{0.03 \mathrm{~V}_{\mathrm{SHE}}-\left(-0.65 \mathrm{~V}_{\mathrm{SHE}}\right)}=\frac{44 \mathrm{~cm}^{-1}}{0.68 \mathrm{~V}}=65 \mathrm{~cm}^{-1} \mathrm{~V}^{-1}
$$

This slope is significantly higher than that observed individually for each $\mathrm{pH}$ value. On the other hand, when the same adlayer is studied at different $\mathrm{pH}$ values, i.e., for adlayers formed in $0.1 \mathrm{M} \mathrm{H}_{2} \mathrm{SO}_{4}$ at $0.100 \mathrm{~V}_{\mathrm{RHE}}$ and the IR spectra recorded in $0.1 \mathrm{M} \mathrm{H}_{2} \mathrm{SO}_{4}$ or $0.1 \mathrm{M}$ 
$\mathrm{NaOH}$, the same Stark tuning slope is found in the whole range of potentials (versus SHE) ${ }^{69}$ The different slopes in acidic and alkaline media clearly indicate that the structure of the adlayer is different. Previous results have suggested that the adlayers formed at $0.100 \mathrm{~V}_{\mathrm{RHE}}$ in alkaline media would have higher number of defects that those formed in acidic solutions. The results presented here support this hypothesis. The presence of defects in the adlayer of the (111) terrace shifts the wave numbers of the $\mathrm{CO}$ band to lower values. ${ }^{39}$ The values of $\mathrm{v}_{\mathrm{CO}}{ }^{L}$ measured here are lower than those predicted from the values measured in acidic solutions, indicating that the $\mathrm{CO}$ adlayer contains a higher number of defects than those formed in acidic solutions. Very similar values for the apparent slope are obtained for the full CO coverage on the stepped surfaces, with values raging between 65 and $74 \mathrm{~cm}^{-1} \mathrm{~V}^{-1}$, significantly higher than those measured in acidic or alkaline, which again reinforces the different surface structure of the CO on the (111) terraces, irrespectively of the width.

For experiments involving CO only on the top of the steps of $\mathrm{Pt}(332)$, at a potential of $0.10 \mathrm{~V}_{\mathrm{RHE}}$, it was found a $v_{\mathrm{CO}^{L}} \simeq 2023 \mathrm{~cm}^{-1}$ in an $0.1 \mathrm{M} \mathrm{HClO}_{4}$ solution (unpublished data), and a $v_{\mathrm{CO}}{ }^{L} \simeq 1964 \mathrm{~cm}^{-1}$ in alkaline solution (Table 1), that is a change of $\Delta v_{\mathrm{CO}}{ }^{L} \simeq 59 \mathrm{~cm}^{-1}$. Then, for the CO only on the top of the steps of the $\operatorname{Pt}(332)$, this resulted in a $\Delta v_{\mathrm{CO}^{L}} / \Delta E \simeq 75 \mathrm{~cm}^{-1}$ $\mathrm{V}^{-1}$, which is the same value than that obtained for in alkaline media (Table 1). The constant value of the Stark tuning slope in the whole $\mathrm{pH}$ range clearly indicates that the structure of the $\mathrm{CO}$ adlayer formed only on the topside of the steps is $\mathrm{pH}$ independent.

\subsection{Influence on $\mathrm{CO}_{a d s}$ Binding Sites}

The changes in the band intensities for linearly and bridge-bonded $\mathrm{CO}$ were determined by comparing the $A_{\mathrm{CO}^{B}:} A_{\mathrm{CO}^{L}}$ ratios for different electrodes at the same potential (on the RHE scale), assuming full CO coverage. Due to the intensity transfer between bands, and the possible different molar absorption coefficients, the absolute ratio between these two configurations cannot be determined. However, comparison of the $A_{\mathrm{CO}^{B}: A_{\mathrm{CO}^{L}}}$ ratios for different Pt surfaces can be used to determine changes in the adlayer structure because it could be assumed that changes in the $A_{\mathrm{CO}^{B}:} A_{\mathrm{CO}^{L}}$ ratio were mainly due to changes in the composition of the $\mathrm{CO}$ binding sites. From the spectra, it can be determined that the band corresponding to linearly bonded $\mathrm{CO}$ for full coverage was dominant for stepped surfaces of the $[(n-1)(111) \times(110)]$ series, increasing in intensity as the width of the (111) terraces decreased. On the other hand, bridge-bonded CO was dominant on the stepped Pt surfaces of 
the $[n(111) \times(100)]$ series, with the band corresponding to this $\mathrm{CO}_{\mathrm{ads}}$ species increasing in intensity as the width of the (111) terraces decreased. For example, for the $\operatorname{Pt}(331) \equiv \operatorname{Pt}(s)$ [2(111) $\times(110)]$ surface (2-atoms-wide (111) terraces), the $A_{\mathrm{CO}^{B}: A_{\mathrm{CO}}^{L}}$ ratio was about $1: 16$, while for the $\operatorname{Pt}(311) \equiv \operatorname{Pt}(\mathrm{s})-[2(111) \times(100)]$ surface (2-atoms-wide (111) terraces), the $A_{\mathrm{CO}^{B}: A_{\mathrm{CO}^{L}}}$ ratio was around 2.3:1 (Table 1). Since the $\mathrm{Pt}(331)$ and $\mathrm{Pt}(311)$ surfaces possess (111) terraces with similar widths, the change in the $A_{\mathrm{CO}^{B}}: A_{\mathrm{CO}^{L}}$ ratio was intrinsically related to the structures of the steps, which are (110) and (100) for $\mathrm{Pt}(331)$ and $\mathrm{Pt}(311)$, respectively. From comparison of these $A_{\mathrm{CO} B}: A_{\mathrm{CO}}{ }^{L}$ ratios, and considering that the band at higher frequencies was dominated by $\mathrm{CO}_{\mathrm{ads}}$ on (111) terraces, it was reasonable to suppose that the change in the composition of the $\mathrm{CO}$ binding sites was related to the influence of the step-type on terrace. In the case of $\mathrm{Pt}(331)$, a band for bridge-bonded $\mathrm{CO}$ was present, albeit of low intensity, while it never appeared for this same stepped Pt surface in acid solution $\left(0.1 \mathrm{M} \mathrm{HClO}_{4}\right)$. In the studies of Rodes et al. ${ }^{39}$ and Hoshi et al., ${ }^{59}$ only a single CO binding geometry was observed for the $\operatorname{Pt}(331)$ surface, attributed to linearly bonded CO. Therefore, the presence of bridgebonded $\mathrm{CO}$ on $\mathrm{Pt}(331)$ in alkaline media suggested that the adlayer formed in acidic solutions has a different structure than that formed in alkaline media, as also suggested by the different Stark tuning slope. In this case, it was not only the surface structure itself that governed the chemistry or composition of the $\mathrm{CO}$ binding sites. The $\mathrm{pH}$ was indirectly related to the change in preference of the $\mathrm{CO}$ binding sites, because the change in solution $\mathrm{pH}$ affected the electric potential or charge on the metal side. For similar potential, on the RHE scale, the interface (metal side) became more negatively charged passing from acid to alkaline solution. According to Gunasooriya et al., ${ }^{70}$ the charge is predominant in determining the geometry (linear and bridge) of the $\mathrm{CO}$ bound on Pt. This preference affects the process of the adlayer formation. Once the adlayer has been formed, and CO is removed from solution, the adlayer remain intact. This mechanism explains the difference between the IR spectra taken in alkaline solutions for adlayers formed at $0.100 \mathrm{~V}_{\mathrm{RHE}}$ in acidic or alkaline solutions. ${ }^{69}$ Bond formation between $\mathrm{CO}$ and transition metals is frequently interpreted in terms of Blyholder's frontier orbital model, ${ }^{71}$ which has been widely discussed in the literature. Then, considering the surfaces of the $\operatorname{Pt}(\mathrm{s})-[n(111) \times(100)]$ series, at more negatively charged electrodes, there is increased stabilization of the bridge-bonded CO present on both (100) steps and short (111) terraces. This is interesting because of under ultra-high vacuum conditions, the band intensity for bridge-bonded CO on $\mathrm{Pt}(211) \equiv \operatorname{Pt}(\mathrm{s})-[3(111) \times(100)]$ surface (3-atoms-wide (111) terraces 
and (100) monoatomic steps), is very small, ${ }^{32}$ or completely absent on $\operatorname{Pt}(322),{ }^{72}$ compared to the band due to linearly bonded CO. Yates et al. ${ }^{61}$ suggested that the formation of bridgebonded $\mathrm{CO}$ on $\mathrm{Pt}(211)$ surfaces could be limited by steric effects related to the terrace width. The present work with CO exclusively on top of the steps revealed that bridge-bonded CO was formed even at the (100) steps, suggesting that the charge also influenced the adsorption of $\mathrm{CO}$ on the (100) structure in aqueous environments.

\section{Main Conclusions}

The influence of the CO binding sites on stepped Pt surfaces was studied by in situ FTIR spectroscopy, comparing the results obtained in alkaline and acid media. The stretching frequencies of $\mathrm{CO}$ exclusively on the top of the steps were, within the experimental error, independent of the width of the (111) terraces of the stepped Pt surfaces. Although surfaces with higher step density accommodated more CO molecules adsorbed on steps, compared to surfaces with wider terraces, there was no change in the $\mathrm{CO}_{\mathrm{ads}}$ band position for $\mathrm{CO}$ only on the top of the steps, indicating that intermolecular coupling was restricted to the $\mathrm{CO}_{\mathrm{ads}}$ along the line of steps. However, for full CO coverage, the structure of the steps and the width of the (111) terraces strongly influenced the CO spectra. Surfaces with the same terrace widths, but with different step orientations, presented different stretching frequencies for both linearly and bridge-bonded $\mathrm{CO}$, as well as different proportions of these $\mathrm{CO}_{\mathrm{ads}}$ binding geometries. The stretching frequencies of $\mathrm{CO}$ on $\mathrm{Pt}(111)$ terraced surfaces were dominated by CO on (111) terraces. Therefore, the changes in both stretching frequency and preference for CO binding sites could be attributed to the influence that the steps exerted on the (111) terraces, with the nature of these changes being dependent on the structure or on the orientation and density of the steps. This fact strongly indicated that the steps affected both physical (such as the stretching frequencies of $\mathrm{CO}$ ) and chemical properties (such as the proportions of linearly and bridge-bonded $\mathrm{CO}$ ) of the (111) terraces of the $\mathrm{Pt}(111)$ terraced surfaces. However, in an aqueous electrochemical environment, the structure of the surface alone was unable to explain all the changes in the chemical properties of the stepped $\mathrm{Pt}$ surfaces, where the negative charge acted to increase the stability of bridge-bonded CO on defect-rich (100) surfaces. 
Acknowledgements: M.J.S.F. is grateful to PNPD/CAPES (Brazil). A.A.T acknowledges CAPES (PROCAD-2013) and CNPq (309066/2013-1). J.M.F. and E.H. thanks the MINECO (Spain) project-CTQ2013-44083-P. C.B.R. also acknowledges Generalitat Valenciana (APOSTD/2017/010). 


\section{References}

1. Gilman, S., The mechanism of electrochemical oxidation of carbon monoxide and methanol on platinum. II. The "Reactant-Pair" mechanism for electrochemical oxidation of carbon monoxide and methanol. J. Phys. Chem. 1964, 68(1), 70-80.

2. Breiter, M. W., Adsorption and oxidation of carbon monoxide on platinized platinum electrodes. J. Phys. Chem. 1968, 72 (4), 1305-1313.

3. Wolter, O.; Heitbaum, J., The adsorption of $\mathrm{CO}$ on a porous Pt-electrode in sulfuric acid studied by DEMS. Ber. Bunsenges. Phys. Chem. 1984, 88(1), 6-10.

4. Bilmes, S. A.; De Tacconi, N. R.; Arvía, A. J., The electrooxidation of chemisorbed co on polycrystalline platinum: A mechanistic interpretation of the anodic current peak multiplicity. J. Electroanal. Chem. 1984, 164 (1), 129-143.

5. Beden, B.; Lamy, C.; de Tacconi, N. R.; Arvia, A. J., The electrooxidation of CO: a test reaction in electrocatalysis. Electrochim. Acta 1990, 35(4), 691-704.

6. Feliu, J. M.; Orts, J. M.; Femandez-Vega, A.; Aldaz, A.; Clavilier, J., Electrochemical studies in sulphuric acid solutions of adsorbed CO on $\mathrm{Pt}(111)$ electrodes. J. Electroanal. Chem. 1990, 296 (1), 191-201.

7. Villegas, I.; Weaver, M. J., Carbon monoxide adlayer structures on platinum (111) electrodes: A synergy between in-situ scanning tunneling microscopy and infrared spectroscopy. J. Chem. Phys. 1994, 101 (2), 1648-1660.

8. Marković, N. M.; Grgur, B. N.; Lucas, C. A.; Ross, P. N., Electrooxidation of CO and $\mathrm{H}_{2} / \mathrm{CO}$ mixtures on $\mathrm{Pt}(111)$ in acid solutions. J. Phys. Chem. B 1999, 103(3), 487-495.

9. Akemann, W.; Friedrich, K. A.; Stimming, U., Potential-dependence of CO adlayer structures on $\mathrm{Pt}(111)$ electrodes in acid solution: evidence for a site selective charge transfer. J. Chem. Phys. 2000, 113 (16), 6864-6874.

10. Maillard, F.; Lu, G. Q.; Wieckowski, A.; Stimming, U., Ru-decorated Pt surfaces as model fuel cell electrocatalysts for CO electrooxidation. J. Phys. Chem. B 2005, 109 (34), 16230-16243.

11. Koper, M. T. M.; Lai, S. C. S.; Herrero, E., Mechanisms of the oxidation of carbon monoxide and small organic molecules at metal electrodes. In Fuel Cell Catalysis, John Wiley \& Sons, Inc.: 2008; pp 159-207.

12. Samjeské, G.; Komatsu, K. I.; Osawa, M., Dynamics of CO oxidation on a polycrystalline platinum electrode: a time-resolved infrared study. J. Phys. Chem. C 2009, 113 (23), 10222-10228.

13. Seung, W. L.; Chen, S.; Sheng, W.; Yabuuchi, N.; Kim, Y. T.; Mitani, T.; Vescovo, E.; Shao-Horn, Y., Roles of surface steps on $\mathrm{Pt}$ nanoparticles in electro-oxidation of carbon monoxide and methanol. J. Am. Chem. Soc. 2009, 131 (43), 15669-15677.

14. Cuesta, Á.; Gutiérrez, C., CO adsorption on platinum electrodes. In Catalysis in Electrochemistry, John Wiley \& Sons, Inc.: 2011; pp 339-373.

15. Wang, H.; Jusys, Z.; Behm, R. J.; Abruña, H. D., New insights into the mechanism and kinetics of adsorbed CO electrooxidation on platinum: online mass spectrometry and kinetic Monte Carlo simulation studies. J. Phys. Chem. C 2012, $116(20), 11040-11053$.

16. Rudnev, A. V.; Kuzume, A.; Fu, Y.; Wandlowski, T., CO oxidation on $\operatorname{Pt}(100)$ : new insights based on combined voltammetric, microscopic and spectroscopic experiments. Electrochim. Acta 2014, 133, 132-145.

17. Liu, H. X.; Tian, N.; Ye, J. Y.; Lu, B. A.; Ren, J.; Huangfu, Z. C.; Zhou, Z. Y.; Sun, S. G., A comparative study of $\mathrm{CO}$ adsorption on tetrahexahedral Pt nanocrystals and interrelated 
Pt single crystal electrodes by using cyclic voltammetry and in situ FTIR spectroscopy. Faraday Discuss. 2014, 176, 409-428.

18. Ciapina, E. G.; Santos, S. F.; Gonzalez, E. R., Electrochemical CO stripping on nanosized Pt surfaces in acid media: a review on the issue of peak multiplicity. J. Electroanal. Chem. 2018, 815, 47-60.

19. Del-Giudice, G.; Tesio, A. Y.; Cappellari, P. S.; Palacios, R. E.; Planes, G. A., Evolution of adsorbed CO on Pt and Pt/Au surface. Electrochim. Acta 2018, 270, 48-53.

20. Yang, S.; Noguchi, H.; Uosaki, K., Electronic structure of $\mathrm{CO}$ adsorbed on electrodeposited $\mathrm{Pt}$ thin layers on polycrystalline $\mathrm{Au}$ electrodes probed by potentialdependent IR/visible double-resonance sum frequency generation spectroscopy. J. Phys. Chem. C 2018, 122 (15), 8191-8201.

21. Wei, J.; Liao, W.-c.; Lei, J.; Yau, S.; Chen, Y.-X., Electrified interfaces of $\operatorname{Pt}(332)$ and $\mathrm{Pt}(997)$ in acid containing CO and KI: as probed by in situ scanning tunneling microscopy. $J$. Phys. Chem. C 2018, 122 (45), 26111-26119.

22. Silva, C. D.; Cabello, G.; Christinelli, W. A.; Pereira, E. C.; Cuesta, A., Simultaneous time-resolved ATR-SEIRAS and CO-charge displacement experiments: the dynamics of CO adsorption on polycrystalline Pt. J. Electroanal. Chem. 2017, 800, 25-31.

23. Ren, X.; Gobrogge, E. A.; Lundgren, C. A., Titrating Pt surface with CO molecules. $J$. Phys. Chem. Lett. 2019, 10 (20), 6306-6315.

24. Podlovchenko, B. I.; Gladysheva, T. D., Determining magnitude of the carbon monoxide adsorption on electrodes of platinum metals. Russ. J. Electrochem. 2002, 38 (4), 349-355.

25. Farias, M. J. S.; Busó-Rogero, C.; Vidal-Iglesias, F. J.; Solla-Gullón, J.; Camara, G. A.; Feliu, J. M., Mobility and oxidation of adsorbed CO on shape-controlled Pt nanoparticles in acidic medium. Langmuir 2017, 33(4), 865-871.

26. Koper, M. T. M., Structure sensitivity and nanoscale effects in electrocatalysis. Nanoscale 2011, 3(5), 2054-2073.

27. Farias, M. J. S.; Feliu, J. M., Determination of specific electrocatalytic sites in the oxidation of small molecules on crystalline metal surfaces. Topics Curr. Chem. 2019, 377(1), 5.

28. Podlovchenko, B. I., Electrical double layer structure on electrodes of platinum metals: effect of the carbon monoxide adsorption. Russ. J. Electrochem. 2004, 40 (11), 11321140.

29. Arán-Ais, R. M.; Figueiredo, M. C.; Vidal-Iglesias, F. J.; Climent, V.; Herrero, E.; Feliu, J. M., On the behavior of the $\mathrm{Pt}(100)$ and vicinal surfaces in alkaline media. Electrochim. Acta 2011, 58, 184-192.

30. Tornquist, W.; Guillaume, F.; Griffin, G. L., Vibrational behavior of carbon monxide adsorbed on platinum in nonacidic electrolytes. Langmuir 1987, 3(4), 477-483.

31. Couto, A.; Rincón, A.; Pérez, M. C.; Gutiérrez, C., Adsorption and electrooxidation of carbon monoxide on polycrystalline platinum at pH 0.3-13. Electrochim. Acta 2001, 46 (9), 1285-1296.

32. Creighan, S. C.; Mukerji, R. J.; Bolina, A. S.; Lewis, D. W.; Brown, W. A., The adsorption of $\mathrm{CO}$ on the stepped $\mathrm{Pt}\{211\}$ surface: a comparison of theory and experiment. Catal. Lett. 2003, 88 (1), 39-45.

33. Buso-Rogero, C.; Herrero, E.; Bandlow, J.; Comas-Vives, A.; Jacob, T., CO oxidation on stepped-Pt(111) under electrochemical conditions: insights from theory and experiment. Phys. Chem. Chem. Phys. 2013, 15 (42), 18671-18677. 
34. Ferre-Vilaplana, A.; Gisbert, R.; Herrero, E., On the electrochemical properties of platinum stepped surfaces vicinal to the (100) pole. A computational study. Electrochim. Acta 2014, 125, 666-673.

35. Tolmachev, Y. V.; Menzel, A.; Tkachuk, A. V.; Chu, Y. S.; You, H., In situ surface Xray scattering observation of long-range ordered $(19 \times 19) R 23.4^{\circ}-13 \mathrm{CO}$ structure on $\mathrm{Pt}(111)$ in aqueous electrolytes. Electrochem. Solid-State Lett. 2004, 7(3), E23-E26.

36. Wakisaka, M.; Ohkanda, T.; Yoneyama, T.; Uchida, H.; Watanabe, M., Structures of a $\mathrm{CO}$ adlayer on a $\mathrm{Pt}(100)$ electrode in $\mathrm{HClO}_{4}$ solution studied by in situ STM. Chem. Commun. 2005, (21), 2710-2712.

37. Mehandru, S. P.; Anderson, A. B., Potential-induced variations in properties for carbon monoxide adsorbed on a platinum electrode. J. Phys. Chem. 1989, 93 (5), 2044-2047.

38. Koper, M. T. M.; van Santen, R. A., Electric field effects on CO and NO adsorption at the $\operatorname{Pt}(111)$ surface. J. Electroanal. Chem. 1999, 476 (1), 64-70.

39. Rodes, A.; Gómez, R.; Feliu, J. M.; Weaver, M. J., Sensitivity of compressed carbon monoxide adlayers on platinum(III) electrodes to long-range substrate structure: Influence of monoatomic steps. Langmuir 2000, 16 (2), 811-816.

40. Severson, M. W.; Stuhlmann, C.; Villegas, I.; Weaver, M. J., Dipole-dipole coupling effects upon infrared spectroscopy of compressed electrochemical adlayers: Application to the $\mathrm{Pt}(111) / \mathrm{CO}$ system. J. Chem. Phys. 1995, 103(22), 9832-9843.

41. García.G; Rodríguez, P.; Rosca, V.; Koper, M. T. M., Fourier transform infrared spectroscopy study of CO electro-oxidation on Pt(111) in alkaline media. Langmuir 2009, 25 (23), 13661-13666.

42. Persson, B. N. J.; Ryberg, R., Vibrational interaction between molecules adsorbed on a metal surface: the dipole-dipole interaction. Phys. Rev. B 1981, 24 (12), 6954-6970.

43. Moskovits, M.; Hülse, J. E., Frequency shifts in the spectra of molecules adsorbed on metals, with emphasis on the infrared spectrum of adsorbed CO. Surf. Sci. 1978, 78(2), 397418.

44. Severson, M. W.; Stuhlmann, C.; Villegas, I.; Weaver, M. J., Dipole-dipole coupling effects upon infrared spectroscopy of compressed electrochemical adlayers: application to the Pt(111)/CO system. J. Chem. Phys. 1995, 103(22), 9832-9843.

45. Kim, C. S.; Korzeniewski, C., Vibrational coupling as a probe of adsorption at different structural sites on a stepped single-crystal electrode. Anal. Chem. 1997, 69 (13), 2349-2353.

46. Farias, M. J. S.; Herrero, E.; Feliu, J. M., Site selectivity for CO adsorption and stripping on stepped and kinked platinum surfaces in alkaline medium. J. Phys. Chem. C 2013, 117(6), 2903-2913.

47. Farias, M. J. S.; Camara, G. A.; Feliu, J. M., Understanding the CO preoxidation and the intrinsic catalytic activity of step sites in stepped Pt surfaces in acidic medium. J. Phys. Chem. C 2015, 119 (35), 20272-20282.

48. Lang, B.; Joyner, R. W.; Somorjai, G. A., Low energy electron diffraction studies of high index crystal surfaces of platinum. Surf. Sci. 1972, 30(2), 440-453.

49. Attard, G. A., Electrochemical studies of enantioselectivity at chiral metal surfaces. J. Phys. Chem. B 2001, 105 (16), 3158-3167.

50. Clavilier, J.; Armand, D.; Sun, S. G.; Petit, M., Electrochemical adsorption behaviour of platinum stepped surfaces in sulphuric acid solutions. J. Electroanal. Chem. 1986, 205 (12), 267-277.

51. Iwasita, T.; Nart, F. C., In situ infrared spectroscopy at electrochemical interfaces. Prog. Surf. Sci. 1997, 55(4), 271-340. 
52. Farias, M. J. S.; Mello, G. A. B.; Tanaka, A. A.; Feliu, J. M., Site-specific catalytic activity of model platinum surfaces in different electrolytic environments as monitored by the CO oxidation reaction. J. Catal. 2017, 345, 216-227.

53. Clavilier, J.; El Achi, K.; Rodes, A., In situ probing of step and terrace sites on $\mathrm{Pt}(\mathrm{S})-$ $[n(111) \times(111)]$ electrodes. Chem. Phys. 1990, 141 (1), 1-14.

54. Spendelow, J. S.; Goodpaster, J. D.; Kenis, P. J. A.; Wieckowski, A., Mechanism of CO oxidation on $\mathrm{Pt}(111)$ in alkaline media. J. Phys. Chem. B 2006, 110 (19), 9545-9555.

55. Batista, E. A.; Iwasita, T.; Vielstich, W., Mechanism of stationary bulk CO oxidation on Pt(111) electrodes. J. Phys. Chem. B 2004, 108 (38), 14216-14222.

56. Lagutchev, A.; Lu, G. Q.; Takeshita, T.; Dlott, D. D.; Wieckowski, A., Vibrational sum frequency generation studies of the $(2 \times 2) \rightarrow(\sqrt{19} \times \sqrt{19})$ phase transition of $\mathrm{CO}$ on $\operatorname{Pt}(111)$ electrodes. J. Chem. Phys. 2006, 125 (15), 154705.

57. Kim, C. S.; Korzeniewski, C.; Tornquist, W. J., Site specific co-adsorption at $\operatorname{Pt}(335)$ as probed by infrared spectroscopy: structural alterations in the $\mathrm{CO}$ adlayer under aqueous electrochemical conditions. J. Chem. Phys. 1994, 100 (1), 628-630.

58. Iwasita, T.; Rodes, A.; Pastor, E., Vibrational spectroscopy of carbonate adsorbed on $\mathrm{Pt}(111)$ and $\mathrm{Pt}(110)$ single-crystal electrodes. J. Electroanal. Chem. 1995, 383 (1-2), 181-189.

59. Hoshi, N.; Tanizaki, M.; Koga, O.; Hori, Y., Configuration of adsorbed CO affected by the terrace width of $\mathrm{Pt}(\mathrm{S})-[n(111) \times(111)]$ electrodes. Chem. Phys. Lett. 2001, 336(1), 13-18.

60. Rodríguez, P.; García, G.; Herrero, E.; Feliu, J. M.; Koper, M. T. M., Effect of the surface structure of $\operatorname{Pt}(100)$ and $\operatorname{Pt}(110)$ on the oxidation of carbon monoxide in alkaline solution: an FTIR and electrochemical study. Electrocatal. 2011, 2 (3), 242-253.

61. Xu, J.; Yates, J. T., Terrace width effect on adsorbate vibrations: a comparison of $\operatorname{Pt}(335)$ and $\operatorname{Pt}(112)$ for chemisorption of CO. Surf. Sci. 1995, 327(3), 193-201.

62. Mukerji, R. J.; Bolina, A. S.; Brown, W. A., A RAIRS and TPD investigation of the adsorption of CO on Pt\{211\}. Surf. Sci. 2003, 527(1), 198-208.

63. Rizo, R.; Sitta, E.; Herrero, E.; Climent, V.; Feliu, J. M., Towards the understanding of the interfacial pH scale at $\mathrm{Pt}(111)$ electrodes. Electrochim. Acta 2015, 162 (0), 138-145.

64. Koper, M. T. M.; van-Santen, R. A.; Wasileski, S. A.; Weaver, M. J., Field-dependent chemisorption of carbon monoxide and nitric oxide on platinum-group (111) surfaces: Quantum chemical calculations compared with infrared spectroscopy at electrochemical and vacuum-based interfaces. J. Chem. Phys. 2000, 113(10), 4392-4407.

65. Wasileski, S. A.; Koper, M. T. M.; Weaver, M. J., Field-dependent chemisorption of carbon monoxide on platinum-group (111) surfaces. Relationships between binding energetics, geometries, and vibrational properties as assessed by density functional theory. $J$. Phys. Chem. B 2001, 105 (17), 3518-3530.

66. Wasileski, S. A.; Weaver, M. J.; Koper, M. T. M., Potential-dependent chemisorption of carbon monoxide on platinum electrodes: new insight from quantum-chemical calculations combined with vibrational spectroscopy. J. Electroanal. Chem. 2001, 500(1-2), 344-355.

67. Chang, S. C.; Jiang, X.; Roth, J. D.; Weaver, M. J., Influence of potential on metaladsorbate structure: solvent-independent nature of infrared spectra for platinum(111) carbon monoxide. J. Phys. Chem. 1991, 95 (14), 5378-5382.

68. Jiang, X.; Weaver, M. J., The role of interfacial potential in adsorbate bonding: electrode potential-dependent infrared spectra for saturated $\mathrm{CO}$ adlayers on $\operatorname{Pt}(110)$ and related electrochemical surfaces in varying solvent environments. Surf. Sci. 1992, 275 (3), 237252. 
69. Farias, M. J. S.; Busó-Rogero, C.; Gisbert, R.; Herrero, E.; Feliu, J. M., Influence of the $\mathrm{CO}$ adsorption environment on its reactivity with (111) terrace sites in stepped Pt electrodes under alkaline media. J. Phys. Chem. C 2014, 118(4), 1925-1934.

70. Kalhara Gunasooriya, G. T. K.; Saeys, M., CO adsorption site preference on platinum: charge is the essence. ACS Catal. 2018, 8 (5), 3770-3774.

71. Blyholder, G., Molecular orbital view of chemisorbed carbon monoxide. J. Phys. Chem. 1964, 68(10), 2772-2777.

72. Walsh, A. J.; Lent, R. v.; Auras, S. V.; Gleeson, M. A.; Berg, O. T.; Juurlink, L. B. F., Step-type and step-density influences on $\mathrm{CO}$ adsorption probed by reflection absorption infrared spectroscopy using a curved $\operatorname{Pt}(111)$ surface. J. Vac. Sci. Technol. A. 2017, 35 (3), 03E102. 
Table 1. Frequencies and ratios of the integrated intensities of linearly and bridge-bonded CO on stepped Pt single crystal surfaces in $0.1 \mathrm{M} \mathrm{NaOH}$ solution, at potential of $0.100 \mathrm{~V}_{\mathrm{RHE}} \cdot v_{\mathrm{CO}}{ }^{L}$ and $v_{\mathrm{CO}^{B}}$ are the stretching frequencies of linearly and bridge-bonded $\mathrm{CO}$, respectively, for a full CO coverage; $v_{\mathrm{CO}^{L}}(s)$ and $v_{\mathrm{CO}^{B}}(s)$ are the stretching frequencies of linearly and bridgebonded CO, respectively, for the experiments with $\mathrm{CO}$ only on the top side of the steps. $A_{\mathrm{CO}}{ }^{B}$ : $A_{\mathrm{CO}}{ }^{L}$ is the ratio of the integrated band intensities for bridge and linearly bonded CO, under the condition of full CO coverage, for spectra recorded at a potential of $0.100 \mathrm{~V}_{\text {RHE }}$.

\begin{tabular}{lccccr}
\hline \multicolumn{1}{c}{ Electrode } & $\boldsymbol{v}_{\mathbf{C O}^{L} / \mathbf{c m}^{-1}}$ & $\boldsymbol{v}_{\mathbf{C O}^{B} / \mathbf{c m}^{-1}}$ & $\boldsymbol{v}_{\mathbf{C O}^{L} / \mathbf{c m}^{-1}(\boldsymbol{s})}$ & $\boldsymbol{v}_{\mathbf{C O}^{B} / \mathbf{c m}^{-1}(\boldsymbol{s})}$ & $\boldsymbol{A}_{\mathbf{C O}^{B}: \boldsymbol{A}_{\mathbf{C O}}{ }^{L}}$ \\
\hline $\operatorname{Pt}(17,17,15)$ & 2017 & 1796 & 1964 & - & $1: 2$ \\
$\operatorname{Pt}(17,15,15)$ & 2012 & 1805 & 1961 & 1747 & $1: 1$ \\
$\operatorname{Pt}(332)$ & 2016 & 1817 & 1962 & - & $1: 3.2$ \\
$\operatorname{Pt}(322)$ & 2008 & 1819 & - & - & $1: 1$ \\
$\operatorname{Pt}(331)$ & 2036 & 1828 & - & - & $1: 16$ \\
$\operatorname{Pt}(311)$ & 1980 & 1843 & - & - & $2.3: 1$ \\
$\operatorname{Pt}(531)$ & 2004 & 1780 & - & - & - \\
\hline
\end{tabular}


Figures
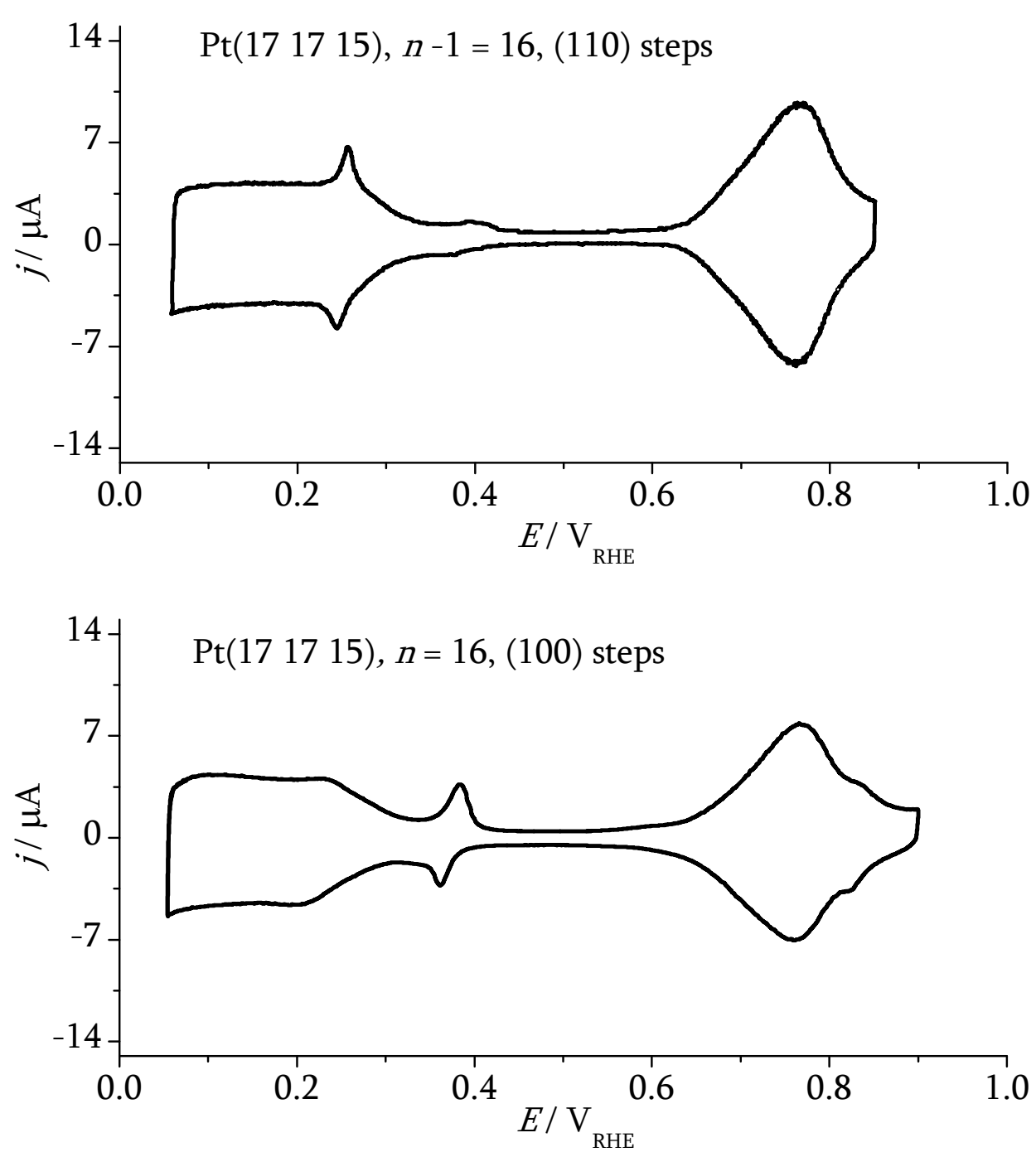

Figure 1. Voltammetric profiles for two stepped Pt surfaces in $0.1 \mathrm{M} \mathrm{NaOH}$ solution. Data recorded at a scan rate of $0.05 \mathrm{~V} \mathrm{~s}^{-1}$. 


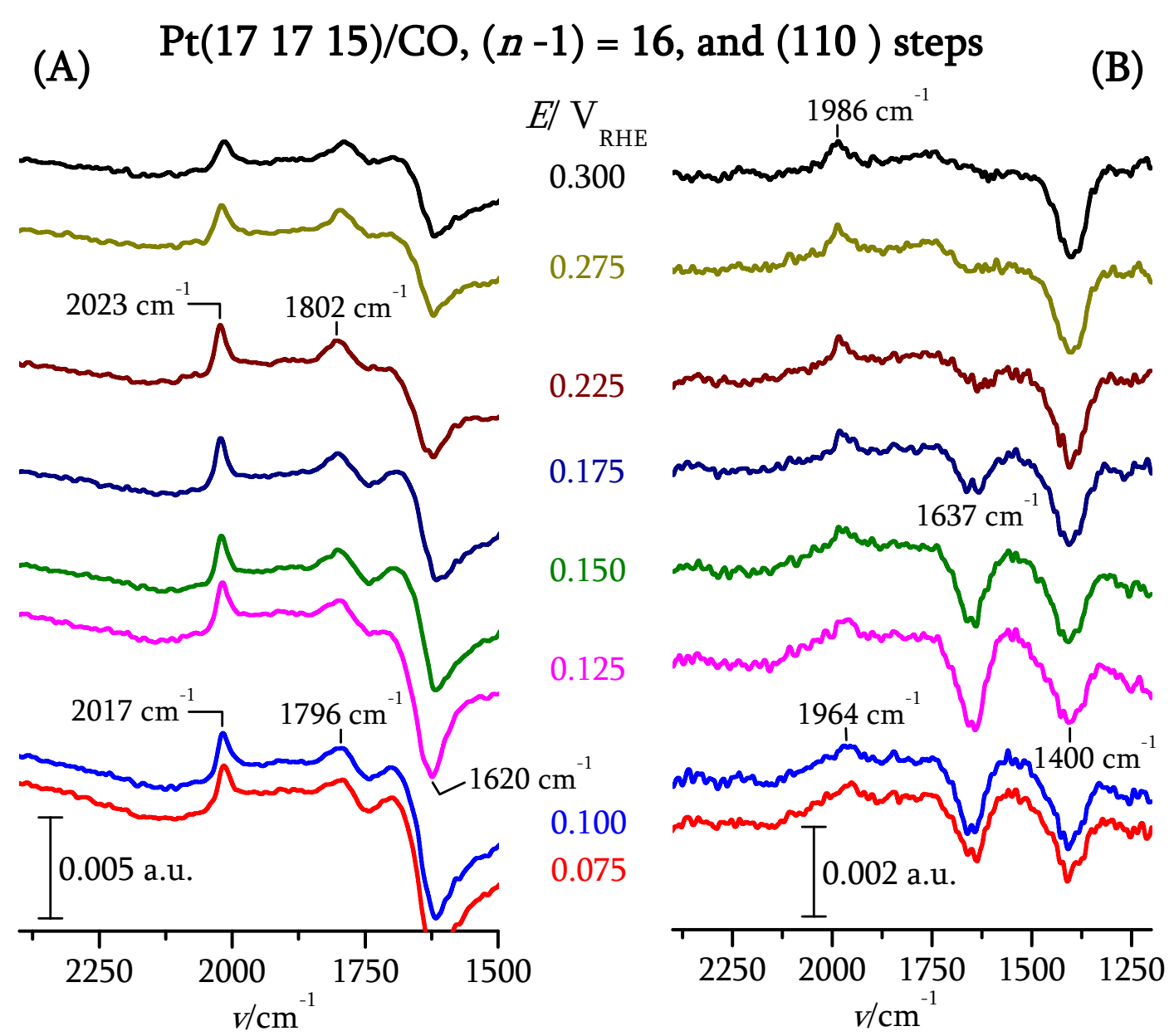

Figure 2. In situ FTIR spectra for adsorbed $\mathrm{CO}$ on a $\operatorname{Pt}(1717$ 15) surface in $0.1 \mathrm{M} \mathrm{NaOH}$ solution, at different potentials: A) full CO coverage; B) CO exclusively on the top side of the (110) steps. The reference spectrum was acquired at a potential of $0.90 \mathrm{~V}$. 

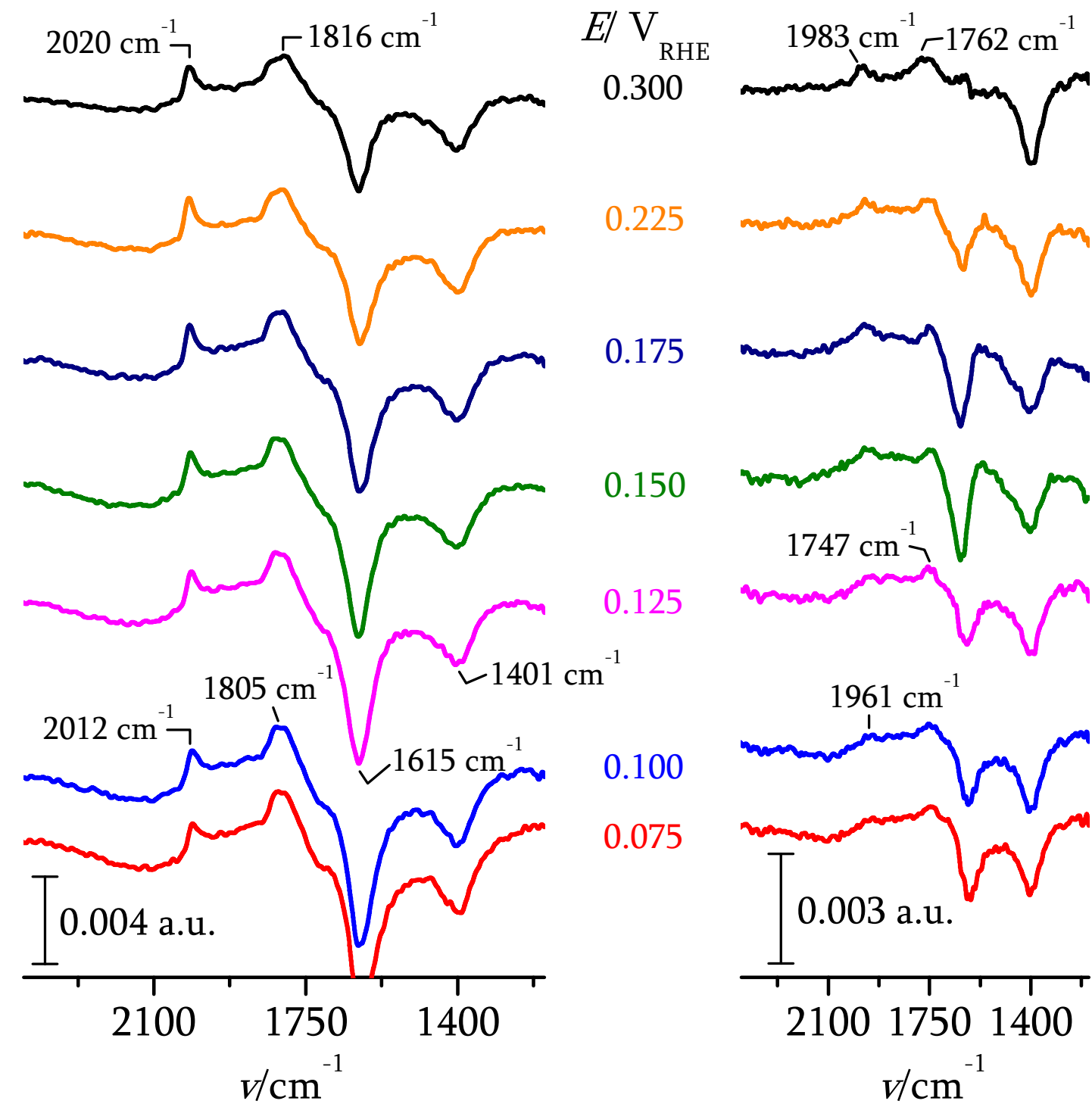

0.225

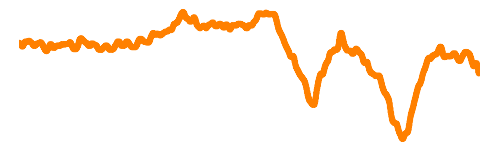

0.175

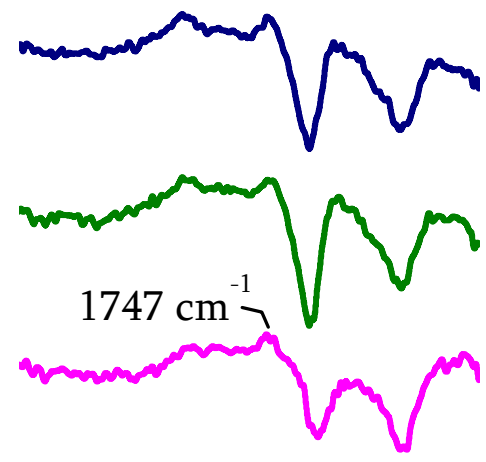

0.125

0.150

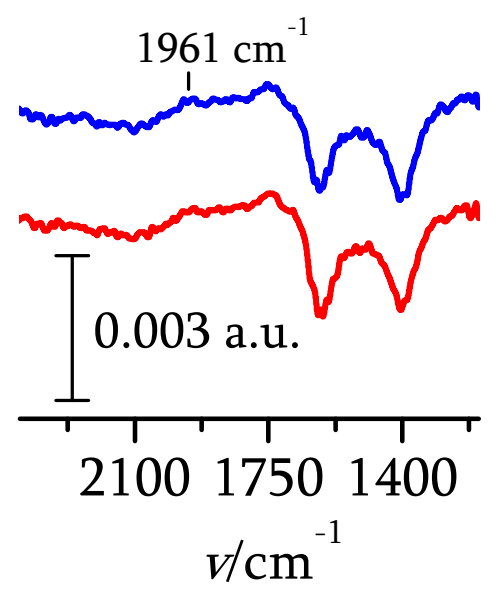

Figure 3. In situ FTIR spectra for adsorbed $\mathrm{CO}$ on a $\operatorname{Pt}(1715$ 15) surface in $0.1 \mathrm{M} \mathrm{NaOH}$ solution, at different potentials: A) full CO coverage; B) CO exclusively on the top side of the (100) steps. The reference spectrum was acquired at a potential of $0.90 \mathrm{~V}$. 
(A) $\quad \operatorname{Pt}(332) / C O,(n-1)=5$, and (110 ) steps

(B)

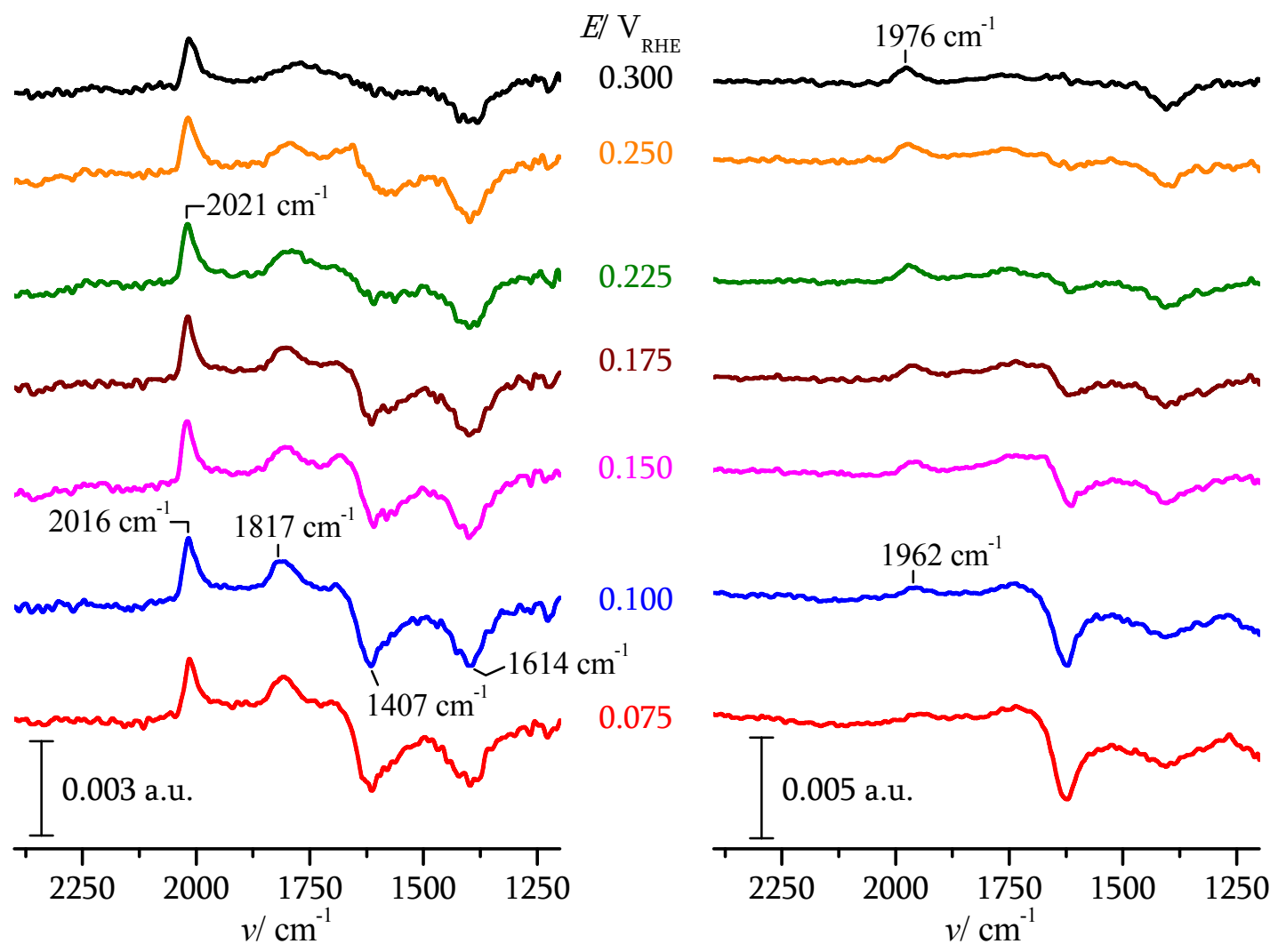

Figure 4. In situ FTIR spectra for adsorbed $\mathrm{CO}$ on a $\mathrm{Pt}(332)$ surface in $0.1 \mathrm{M} \mathrm{NaOH}$ solution, at different potentials: A) full CO coverage; B) CO exclusively on the top side of the (110) steps. The reference spectrum was acquired at a potential of $0.90 \mathrm{~V}$. 

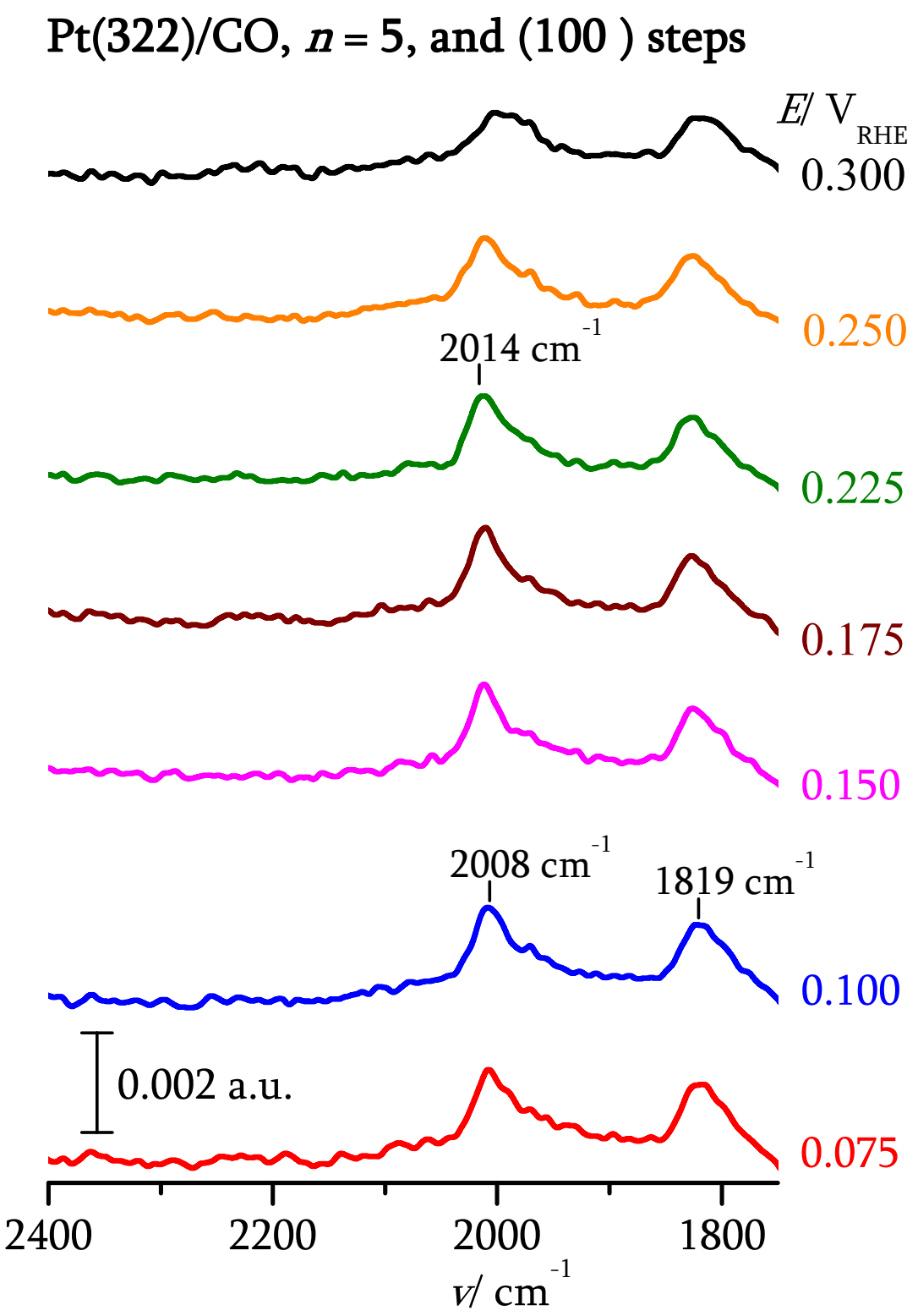

Figure 5. In situ FTIR spectra for full CO coverage on a $\mathrm{Pt}(322)$ surface in $0.1 \mathrm{M} \mathrm{NaOH}$ solution, at different potentials. The reference spectrum was acquired at a potential of $0.90 \mathrm{~V}$. 
$\mathrm{Pt}(331) / \mathrm{CO},(n-1)=2$, and $(110)$ steps

(A)

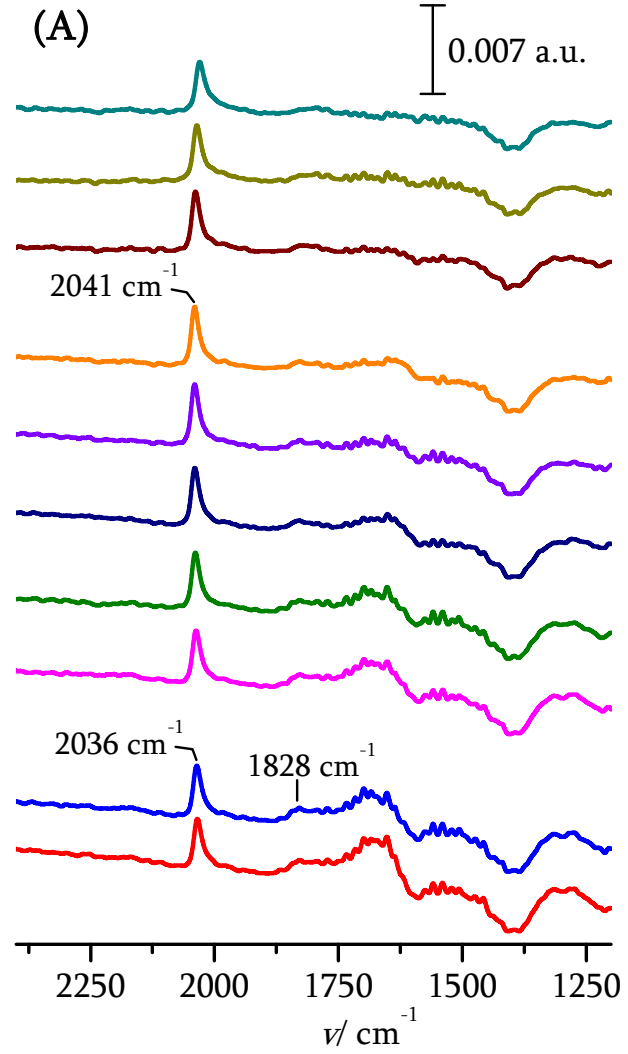

$\operatorname{Pt}(311) / C O, n=2$, and (100) steps

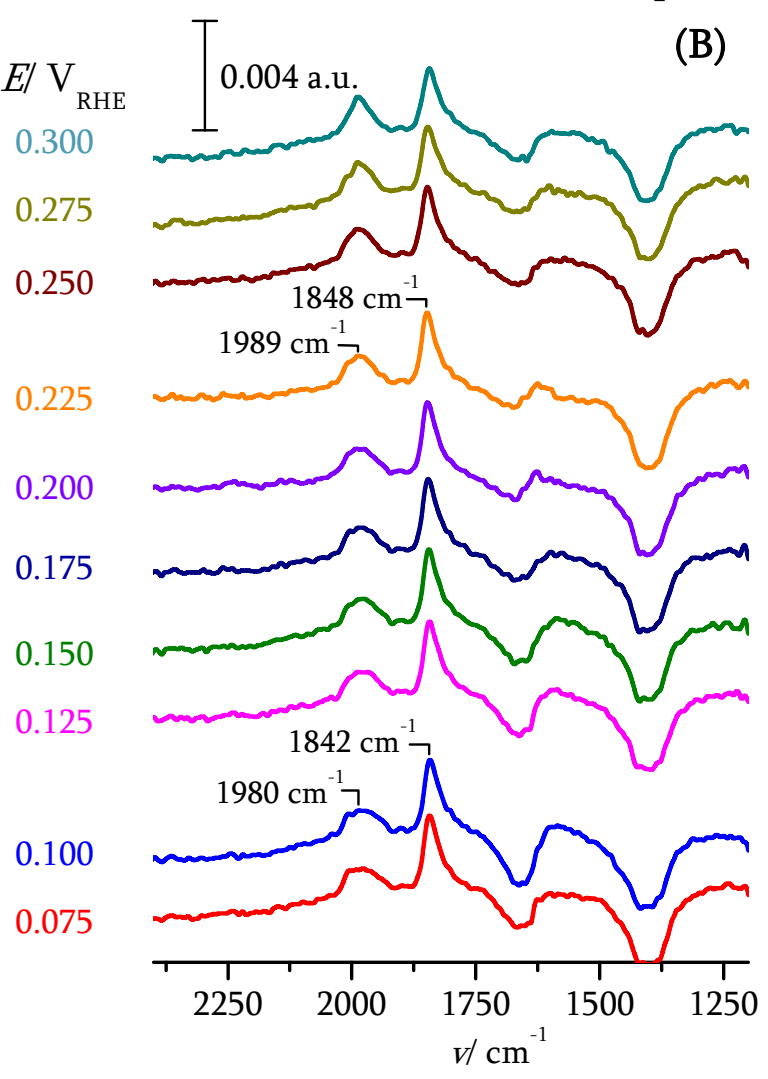

Figure 6. In situ FTIR spectra for full CO coverage on $\mathrm{Pt}(331)$ and $\mathrm{Pt}(311)$ surfaces in $0.1 \mathrm{M}$ $\mathrm{NaOH}$ solution, at different potentials. The reference spectrum was acquired at a potential of $0.90 \mathrm{~V}$. 


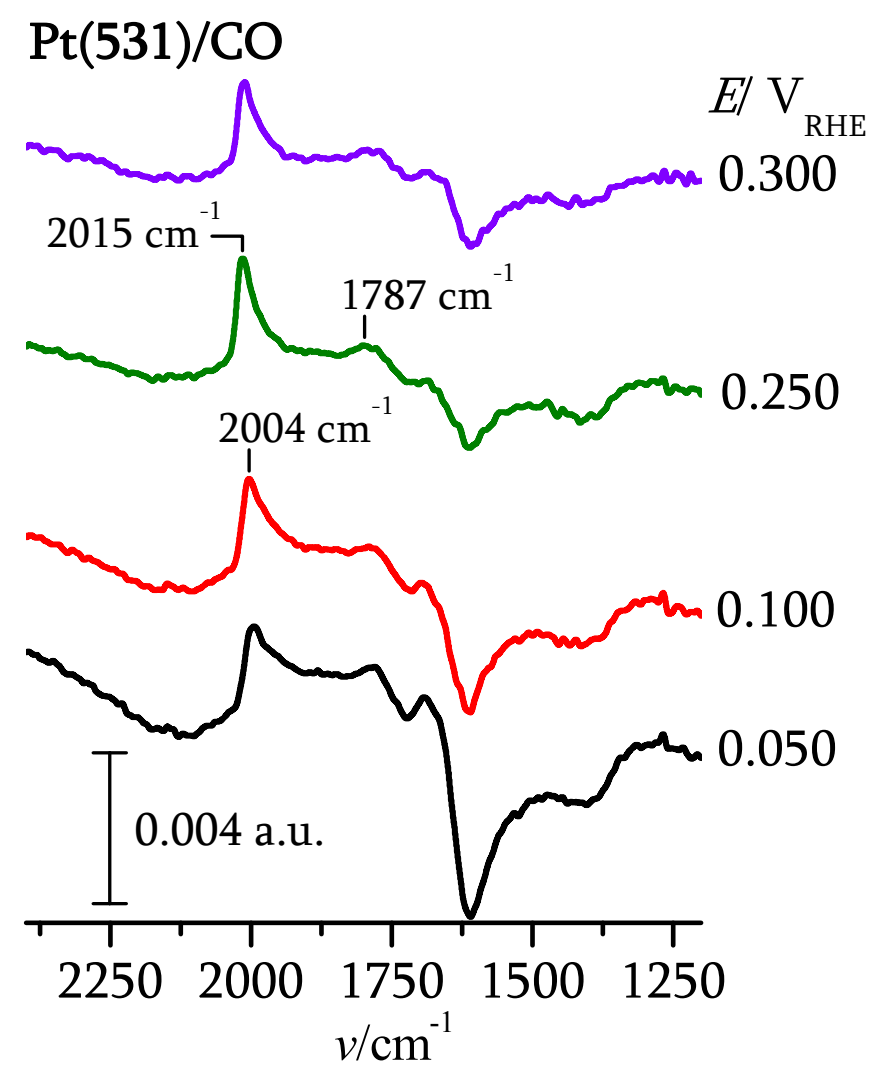

Figure 7. In situ FTIR spectra for full CO coverage on a $\operatorname{Pt}(531)$ surface in $0.1 \mathrm{M} \mathrm{NaOH}$ solution, at different potentials. The reference spectrum was acquired at a potential of $0.90 \mathrm{~V}$. 


\section{Graphical Abstract}

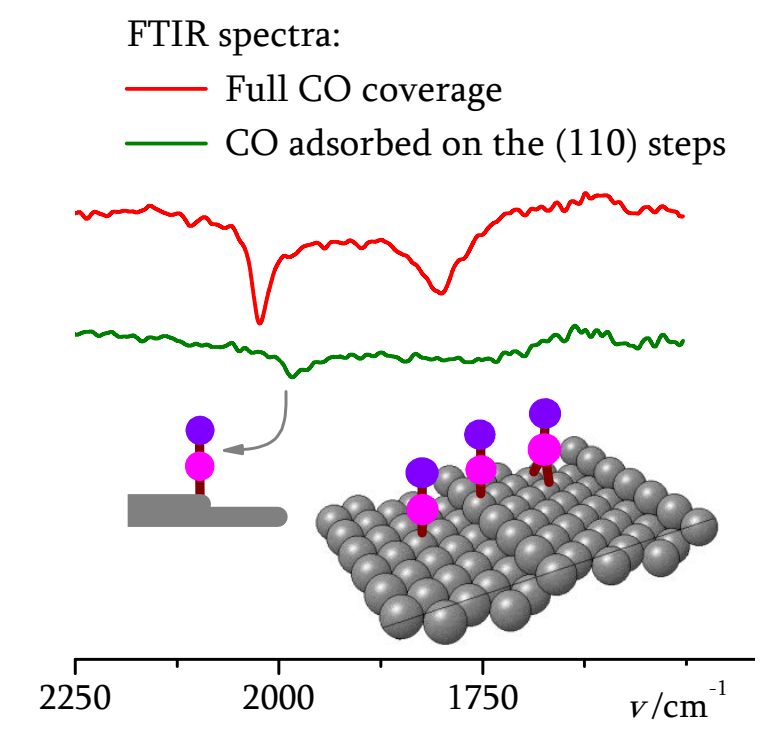

